\title{
The Role of the Ventro-Lateral Prefrontal Cortex in Idiom Comprehension: An rTMS Study
}

\author{
Katja I. Häuser ${ }^{1,2}$, Debra A. Titone ${ }^{2,3}, \&$ Shari R. Baum ${ }^{1,2}$ \\ ${ }^{1}$ School of Communication Sciences and Disorders, ${ }^{2}$ Centre for Research on Brain, Language \\ and Music, ${ }^{3}$ Department of Psychology, McGill University, Montreal, Canada
}

\section{Keywords}

idioms, TMS, prefrontal cortex, cognitive control, inhibition

\section{Corresponding author}

Katja Häuser

Köhlerweg 15

90596 Schwanstetten

katja.haeuser@mail.mcgill.ca 


\section{Highlights}

- Prior work using fMRI and rTMS conflicts regarding whether the ventro-lateral PFC (VLPFC), a convergence zone for semantic control, is recruited during idiom comprehension.

- We examined whether a virtual lesion induced by repetitive TMS (rTMS) in the VLPFC impaired idiom comprehension as a function of idiom familiarity and individual differences in cognitive control.

- $\quad$ rTMS to the VLPFC impaired the comprehension of low-familiar idioms in individuals with high levels of cognitive control.

- $\quad$ Our data cohere with other work showing the VLPFC to be implicated when multiple semantic representations viable, as in the case of low-familiar idioms. High-control individuals may be more susceptible to rTMS-induced disruptions, because they rely more on VLPFC integrity during semantic processing. 


\begin{abstract}
Previous research is equivocal with respect to the neural substrates of idiom processing. Particularly elusive is the role of the ventro-lateral prefrontal cortex (VLPFC), a region implicated in semantic control generally. Although fMRI studies have shown that the VLPFC is active during idiom processing, rTMS studies have failed to corroborate a clear role of this prefrontal region.
\end{abstract}

We investigated this issue using a semantic meaningfulness judgment task that compared idiom comprehension following rTMS-stimulation to the VLPF, relative to a control site (vertex). We also investigated whether differences among comprehenders in general cognitive capacity modulated the effects of rTMS.

The results suggest that the processing of low-familiar idioms is particularly disrupted by VLPFC stimulation, potentially because these items involve a maximal semantic conflict between a salient literal and less-known figurative meaning. Of note, this pattern only emerged in individuals with higher cognitive control capacity, indicating that these individuals relied particularly on VLPFC integrity. Taken together, the results corroborate prior fMRI studies and illustrate potential boundary conditions linking the VLPFC to idiom processing. 


\section{Introduction}

One aspect of language processing that is particularly challenging is the resolution of semantically ambiguous information across many linguistic levels, for example, words, phrases and sentences. In this paper, we are particularly interested in how this challenge plays out during the comprehension of idiomatic phrases, such as kick the bucket. According to classic definitions, idioms are relatively more complex than "normal" literal language because their figurative meanings (to die) are often distinct from the compositional meaning created by the combination of their constituents (to strike a pail with one's foot; Nunberg, Sag, \& Wasow, 1994). Indeed, according to the traditional view, idioms are nothing more than long words that have arbitrarily stipulated meanings (Bobrow \& Bell, 1973; Swinney \& Cutler, 1979; reviewed in Libben \& Titone, 2008; Titone et al., 2015).

However, the traditional view of idioms may be an oversimplification (Gibbs \& Nayak, 1989; Gibbs, Nayak, \& Cutting, 198; Gibbs \& O’Brien, 1990), given that many idioms have internal semantic structure, and can be modified both semantically and syntactically (e.g. convicted minimalist spills bean, or by and not so large; Gibbs \& Nayak, 1989; MacGlone, Glucksberg, \& Cacciari, 1994). For example, in idioms such as pop the question, the individual component words can be semantically analyzed to contribute in a metaphorical way towards the figurative meaning (e.g. pop refers to a sudden act and the question refers to a marriage proposal; Gibbs, Nayak, \& Cutting, 1989). Thus, to accommodate both the dual holistic and compositional nature of idioms, hybrid or constraint-based views have attributed both word-like and phrase-like qualities to idioms (Titone \& Connine, 1999; Libben \& Titone, 2008).

According to such models, idiom processing involves the simultaneous co-activation of figurative and literal meanings, and the speed with which these representations become available 
is determined by several constraints (Titone \& Libben, 2014; Titone \& Connine, 1999). One such constraint of great relevance to the present investigation is idiom familiarity. Idiom familiarity is typically defined as the degree to which an idiomatic sequence is known in a linguistic community, irrespective of its meaning. Accordingly, high-familiar idioms are overlearned and deeply entrenched within a given linguistic community, and can be recognized as holistic units very quickly, in a way that might potentially trump activation of literal word meanings (Cronk \& Schweigert, 1992; Titone \& Connine, 1994). In contrast, low-familiar idioms are less known within a language community, thus, the literal meanings of the constituent words are more likely to remain active in memory during comprehension.

\subsection{Cognitive control and idiom processing}

A hybrid or constraint-based characterization of idiom processing implies that people frequently activate potentially conflicting semantic representations when they encounter idioms. Consequently, under these circumstances, idiom processing could be computationally more demanding compared to other non-idiomatic aspects of language, and may require the additional recruitment of general cognitive control capacity to resolve any semantic ambiguity that arises (Galinsky \& Glucksberg, 2000; Glucksberg, Newsome, \& Goldvarg, 2001; Papagno \& Vallar, 2001; Titone, Holzmann, \& Levy, 2002; Papagno \& Caporali, 2007).

In neuropsychology, cognitive control has been defined as the top-down regulated and resource-limited capacity of the cognitive system to configure its own performance through appropriate adjustments in behavior (Wood \& Grafman, 2003; Bottvinick, Braver, Barch, Carter, \& Cohen, 2001). For example, increased demands on cognitive control are associated with detecting cognitive conflicts (Bottvinick et al., 2001), inhibiting irrelevant information (Ridderinkhof, Ullsperger, Crone, \& Nieuwenhhuis, 2004), enhancing activation of relevant 
information (Aron, Robbins, \& Poldrack, 2004), as well as monitoring and sending feedback about performed actions and behavior (Wood \& Grafman, 2008). Thus, applied to idiom processing, cognitive control can be used to describe the effortful actions of the cognitive system when faced with evaluating literal and figurative meanings of an idiom against the discourse or sentence context, enhancing activation for figurative meanings, and suppressing activation for literal meanings.

One way to investigate the relationship between idiom processing and cognitive control is by use of clinical patient groups who normally present with impairments in cognitive control. For example, such control-related deficits have been described as a hallmark of Alzheimer's disease or schizophrenia, so it stands to reason that individuals with these disorders would also show idiom-related deficits. Indeed, several studies have shown that this may be the case. For example, Alzheimer's and schizophrenia patients were found to be more likely to associate an idiom with its literal than with its figurative meaning in a sentence-to-picture or sentence-toword matching task (see Papagno, Lucchelli, Muggia et al., 2003; Rassiga, Lucchelli, Crippa et al., 2009; Schettino, Lauro, Crippa et al., 2010). This could suggest that clinical deficits in cognitive control render such individuals unable to sufficiently inhibit the activation of literal phrase meanings when processing an idiom. However, some of these studies may be diminished by the fact that they did not consistently include a literal control condition, which makes it difficult to assess if the reported effects were truly idiom-specific (Rassiga et al., 2009). In other studies where a literal control condition was included, the performance of the clinical patient groups was also impaired in this control task (Schettino et al., 2010). Thus, investigations on clinical patients groups have obtained only preliminary evidence for the hypothesis that idiom 
comprehension requires greater levels of cognitive control than the comprehension of literal language.

Importantly, the findings from studies that have addressed neurotypical individuals without clinical impairments do not support a relationship between idiom processing and cognitive control. For example, a recent study from our group showed that healthy older adults (individuals often reported to experience control-related deficits) are not impaired in understanding the figurative meanings of idioms (Häuser, Sheikh, Columbus et al., in preparation), and indeed, may benefit from longer life-long exposure to language in preferentially processing idioms' figurative meanings. Similarly, another study from our group showed that individual differences in cognitive control do not modulate idiom processing in healthy younger adults (Columbus, Sheikh, Côté-Lecaldare et al., 2014). These findings indicate that any relationship between cognitive control and idiom processing may be specific to clinically-compromised populations, or may only appear under particularly demanding comprehension circumstances. In sum, the neuropsychological evidence for a role of executive functions in idiom processing is rather mixed.

Another way to study the relationship between idiom processing and cognitive control is by using neuroimaging to investigate activation of the prefrontal cortex (PFC), the neural region generally associated with cognitive control (Norman \& Shallice, 1986; Miller \& Cohen, 2001; Duncan, 2001; Goldman-Rakic, 1995; Baddeley \& Della Sala, 1996; for reviews, see Wood \& Grafman, 2008; Ridderinkhof, van den Wildenberg, Segalowitz, \& Carter, 2004; Miller, 2000; Braver, Paxton, Locke et al., 2009; Miller, 2000; MacDonald et al., 2000). Many studies describe the PFC as a neural convergence zone for cognitive control, as it upholds, directs and manipulates representations in working memory to bias willful cognitive actions in a context- 
relevant way (Thompson-Schill, Bedny, \& Goldberg, 2005; see Miller, 2000; Duncan, 2001). As such, the PFC is active during response conflicts, selective attention, or context updating (for reviews see Tanji \& Hoshi, 2008; Koechlin, Ody, \& Kouneiher, 2003; West, 2003; Braver, 2012). This is consistent with a common metaphor that describes the function of this cortical area as a switch operator, which determines which railway track a train will use at any given point in time (Miller, 2000; Wood \& Grafman, 2003). Given that idiom processing involves the sustained co-activation of conflicting semantic representations in working memory (Titone, Columbus, Whitford et al., 2015), it stands to reason that this cortical region may be involved in the processing of idioms as well, a topic to which we now turn in detail.

\subsection{Idiom processing and the prefrontal cortex}

Several neuroimaging studies have implicated the prefrontal cortex during idiom processing. For example, in a recent fMRI study (Hillert \& Buračas, 2009), participants were asked to silently read for comprehension idioms (e.g. She held the torch) and non-idiomatic literal control phrases (e.g. He met her in the mall). According to the results, the contrast idiomatic vs literal phrases activated cortical areas in the dorsolateral prefrontal cortex (DLPFC, BA 9 and 46, see Petrides \& Pandya, 1999; Yeung, 2013; Tanji \& Hoshi, 2008) and also in the ventro-lateral prefrontal cortex (VLPFC; BA 44 and 45 in that study), a prefrontal site slightly inferior to the DLPFC. Thus, this suggests that the semantic conflict between literal and figurative meanings inherent in idioms requires controlled processing that is mediated by the PFC.

Indeed, and of relevance to the present study, several fMRI studies have shown that the ventro-lateral PFC region may be crucial during idiom processing (see Zempleni, Haverkort, Renken, \& Stowe, 2007; Mashal, Faust, Hendler \& Jung-Beeman, 2008; Lauro, Tettamanti, 
Cappa \& Papagno, 2008). For example, Lauro and colleagues (2008) used a sentence-to-picture matching task and asked participants to identify the picture that correctly depicted a previously seen idiomatic (e.g. He has a green thumb) or literal control phrase (e.g. The boy is eating an apple). The distractor showed the opposite meaning of the idiomatic or literal phrase (e.g. for the idiom tirare la cinghia, to be very poor, the distractor showed a rich man dining at a restaurant). According to the results, correct performance on idiom trials activated bilaterally the VLPFC (BA 44 and 45), whereas literal trials activated bilateral parietal areas (BA 40). Thus, this study not only suggests that idioms and literal phrases may be processed in non-overlapping cortical areas, but also that idioms primarily activate the VLPFC, potentially because of the semantic conflict inherent in these expressions. This view is also supported by two recent review papers that investigated the common neural activation sites in several idiom studies (Bohrn, Altmann, \& Jacobs, 2012; Rapp, Mutschler, \& Erb, 2012). Both meta-analyses found that idiomatic vs literal phrases activate a left-lateralized network, with strongest activation in the left middle temporal gyrus (BA 21) and the left VLPFC (Bohrn, Altmann, \& Jacobs, 2012; Rapp, Mutschler, \& Erb, 2012). Thus, even though the meta-analyses and the Lauro et al. (2008) study are not in complete agreement as to the hemispheric lateralization of idiomatic language, they both converge on the view that idioms activate the ventro-lateral PFC.

Such work linking the VLPFC to idiom processing is interesting, in light of other studies that link the VLPFC to the cognitive control of semantic memory generally (ThompsonSchill, D’Esposito, Aguirre, \& Farah, 1997; Thompson-Schill, D’Esposito, \& Kan, 1999; Gabrieli, Poldrack, \& Desmond, 1998; Badre, Poldrack, Pare-Blagoev, Insler, \& Wagner, 2005; Wagner, Pare-Blagoev, Clark \& Poldrack, 2001; Whitney, Kirk, O'Sullivan, et al., 2011; Whitney et al., 2012; for reviews see Badre \& Wagner, 2002, 2007; Thompson-Schill, Bedny \& 
Goldberg, 2005). For example, the VLPFC has been associated with tasks that require the controlled retrieval of semantic representations that are not activated automatically through strong cue-target associations. Such situations include when a target word needs to be retrieved that is only weakly semantically related to a cue word (Badre \& Wagner, 2007; Thompson-Schill et al., 1997). Similarly, the VLPFC is also active in tasks that require post-retrieval selection, for example, when the subordinate meaning of a lexically ambiguous word competes for activation with automatic activation of its dominant meaning (Whitney, Jefferies, \& Kircher, 2011). In both cases, the VLPFC is thought to guide the retrieval of task-relevant semantic information from storage sites in the temporal cortex, either by enhancing activation of task-relevant knowledge or inhibiting task-irrelevant representations (Thompson-Schill et al., 1997; Badre et al., 2005). In light of these observations, the VLPFC may also support the mechanisms that guide the retrieval of figurative and literal meanings of idioms from temporal storage sites, maintain such representations in working memory, and engage in meaning selection by up-regulating activation of figurative meanings while simultaneously down-regulating activation of literal meanings.

However, one potential concern with past studies linking the VLPFC to idiom processing is that they are inherently correlational insofar as they exclusively rely upon the pattern of brain activation measurable when people encounter idioms. Of note, such patterns of activation may be a cause or consequence of comprehension, thus limiting the ability to develop a decisive mechanistic account. A more direct means of experimentally testing the role of the VLPFC in idiom processing is through the use of stimulation paradigms, such as repetitive transcranial magnetic stimulation or rTMS (Pascual-Leone, 1991; Wassermann, 1998). In rTMS, a coil with a rapidly changing current is held above the skull and produces a strong, focal magnetic field, thus creating an 'artificial lesion' in underlying brain tissue (Wassermann, 1998). 
The magnetic field passes painlessly through the skull and transiently introduces noise into neural performance, which in turn can be measured in behavioral tasks. In contrast to research with fMRI, rTMS leads to changes in cognitive performance which can be causally related to a dysfunction of the stimulated neural region (Devlin \& Watkins, 2007).

Of relevance here, several rTMS studies have shown that stimulation to the prefrontal cortex impairs idiom comprehension. However, whereas past fMRI studies implicated both the dorso- and the ventro-lateral PFC, rTMS evidence to date has only supported a role for the dorso-lateral PFC (Fogliata, Rizzo, Reati, Miniussi, Oliveri, \& Papagno, 2007; Rizzo, Sandrini \& Papagno, 2007; Sela, Ivry, \& Lavidor, 2012). For example, two studies found that idiom comprehension was impaired when rTMS was applied to the left (Fogliata et al., 2007) and right DLPFC (Rizzo et al., 2007). In both studies, participants showed a greater bias to choose the literal distractor of an idiom in a sentence-to-picture matching paradigm, suggesting a dysfunctional inhibitory mechanism (guided by the DLPFC) which normally suppresses literal word meanings during idiom comprehension. A similar conclusion was drawn from another idiom study that used transcranial direct current stimulation (tDCS) to simultaneously increase and decrease neural excitability. Sela and colleagues (2012) showed that, when facilitating the left DLPFC and inhibiting the right DLPFC, participants were more accurate relating idioms (bite the bullet) with figurative target words (accept) than with literal target words (flavor). This pattern did not emerge when tDCS stimulation was reversed (i.e. facilitation of the right and inhibition of the left DLPFC), which suggests that particularly the left DLPFC may be crucial to process figurative meanings of idioms. Thus, previous rTMS and tDCS studies are consistent in demonstrating that a stimulation-induced enhancement of prefrontal control mechanisms leads to more successful inhibition of the literal meaning of the idiom. 
However, in contrast with prior work on the dorso-lateral PFC, the only rTMS study examining the VLPFC failed to find any idiom-specific effects (Oliveri et al., 2004). In that investigation, a sentence-to-picture matching task was used to compare the comprehension of idiomatic and matched literal phrases following stimulation to the VLPFC and a baseline without rTMS. Stimulation to the VLPFC led to a general decrease in accuracy for both idiomatic and literal sentences. Thus, it is difficult to interpret these findings specifically with respect to the role of the VLPFC in idiom processing, as opposed to language processing more generally. For example, cortical stimulation to the VLPFC could have caused global performance deficits in a multiple-choice task with several response options. As well, differences among idioms could have led to differential patterns of VLPFC recruitment, however, this was not investigated.

In sum, existing research on the role of the VLPFC in idiom comprehension is divided: fMRI studies support the view that this cortical area is associated with idiom processing, whereas rTMS studies do not clearly support its involvement.

\subsection{The present study}

The goal of the present study was to investigate whether idiom processing relies on neural substrates in the VLPFC through the use of an rTMS paradigm. The experiment addressed three primary questions.

First, we examined whether the VLPFC is specifically implicated in idiom comprehension. Several previous rTMS and fMRI studies (Fogliata et al., 2007; Rizzo et al., 2007; Oliveri et al., 2004; Lauro et al., 2008) used sentence-to-picture matching tasks to assess idiom comprehension. Such tasks may be problematic due to the overt presence of the literal response option and the visuo-spatial difficulties associated with depicting abstract figurative 
meanings (Papagno \& Caporali, 2007; Cacciari \& Papagno, 2012). The present study used a semantic meaningfulness judgment task in an effort to avoid these concerns.

Second, we investigated whether VLPFC demands are modulated by idiom familiarity, which is known to influence idiom processing (Schweigert, 1986; Titone \& Libben, 2014; Titone \& Connine, 1999). We expected that low-familiar idioms, in particular, would be prone to rTMSinduced disruptions, because these phrases involve a maximal semantic conflict between a lessknown figurative meaning and a more salient literal meaning. In contrast, rTMS should only minimally disrupt high-familiar idioms, because they have a highly salient figurative meaning that likely represents a dominant interpretation.

Third, we investigated whether inherent differences among participants in cognitive control capacity (as reflected by the Simon task; Simon \& Berbaum, 1990; Zorzi \& Umiltá, 1995) influence idiom processing. Previous studies supporting the role of executive functions in idiom processing had primarily addressed clinical patient groups, such as individuals with Alzheimer's disease or schizophrenia (Papagno et al., 2003; Schettino et al., 2010; Rassiga et al., 2009; Titone, Levy \& Holzman, 2002). These individuals usually exhibit a range of co-morbid cognitive impairments (for example, memory loss, depression, anxiety or paranoia), making it difficult to attribute any deficits that emerge to reductions in cognitive control.

\section{Method}

\subsection{Participants}

Sixteen native English speakers from the Montreal community between the ages of 18 and 28 years participated in the experiment ( 9 female; mean age $=22.63$ years). They were screened for any relative or absolute contraindications for rTMS (Wassermann, 1998) upon their 
arrival at the laboratory. Informed written consent was obtained from all participants. Participants had no history of speech/language or hearing impairments, as well as no personal or family history of seizures, epilepsy, and psychiatric or neurological disorders. All participants were strongly right-handed, with a mean right-handedness score of 86 (range: $67-100$ ) on the Edinburgh Handedness Inventory (EHI; Oldfield, 1971). ${ }^{1}$ The study was approved by the local research ethics committee. A recent brain scan (T1-weighted, structural scans) and participants' consent to its release were mandatory in order to take part in the study.

\subsection{Design and Procedure}

The design of the study consisted of four predictors, stimulation site (VLPFC vs. vertex, a control site which has no function in language), sentence type (idiomatic vs. literal), idiom familiarity (a scaled variable; obtained from Libben \& Titone, 2008), and cognitive control (another scaled variable; assessed through the Simon task; Blumenfeld \& Marian, 2011, see below). Our dependent variables were the speed and accuracy that participants completed the experimental task (meaningfulness judgments on idiomatic and matched literal sentences). Participants came to our lab twice, corresponding to two sessions of rTMS stimulation (to be detailed below), and performed the experimental task immediately after rTMS stimulation had ceased. The testing sessions were separated by at least one week. The Simon task was only administered once to each subject, during the first testing session prior to the rTMS-paradigm.

\subsection{Experimental Task}

We employed a meaningfulness judgment task for auditorily presented sentences that contained idioms or matched literal phrases. Participants heard idiomatic and literal stimuli over

\footnotetext{
${ }^{1}$ On the EHI a person is right-handed if they have a right-handedness score of more than 40.
} 
closed earphones and indicated, by pressing one of two buttons on a response pad, whether the item they heard was meaningful or not. Task instructions (presented on a screen) read: "In this experiment you will listen to spoken English sentences. Your task is to indicate, by pressing a button, if each sentence is meaningful or not. Before the presentation of a sentence, a fixation cross will appear on the screen in front of you. Once the sentence has ended, the question < Meaningful - NO / YES ? > will appear. Make your judgment by pressing the RIGHT ARROW button for YES (MEANINGFUL), and the LEFT ARROW button for NO (NOT MEANINGFUL). Try to respond as quickly and accurately as possible. Please press Enter to indicate that you are ready to begin the experiment."

All trials began with a fixation cross, displayed in the middle of the screen for $1000 \mathrm{~ms}$, followed by the auditory presentation of the stimulus sentence through closed headphones (type Sennheiser HD 280 pro) in front of a white screen. Time-locked to the offset of the auditory item, the response prompt "Meaningful - NO / YES ?" was displayed on the screen (the order of NO / YES corresponded to the fact that the left arrow button indicated no, non-meaningful and the right arrow button indicated yes, meaningful). The response prompt stayed on the screen until the participant made a response, with the maximal response time set to $4000 \mathrm{~ms}$. If a participant failed to make a response during this time, the computer automatically initiated the next trial.

Task instructions and response prompts appeared on a 17" $(43 \mathrm{~cm})$ by $24 "(61 \mathrm{~cm})$ Dell 32 bit computer monitor with a $60 \mathrm{~Hz}$ refresh rate and a screen resolution of 1680 x 1050 pixels; participants were seated at a distance of about $60 \mathrm{~cm}$ between their eyes and the screen.

\subsection{Stimuli}

To create the experimental stimuli, we selected 54 verb-determiner-noun idioms (kick the bucket, break the ice) from the Libben and Titone (2008) idiom corpus. The idioms ranged 
between high and low-familiar on a scale from 1-7 (1 meaning that the idiom is never encountered, and 7 meaning that the idiom is frequently encountered; mean familiarity $=3.37$; $\mathrm{SD}=0.82$ ). Literal control phrases were created for each idiom by replacing the main verb of the idiom with a verb of approximately the same length that fit the noun semantically; for example, spill the beans (idiomatic) was matched with cook the beans (literal control).

Subsequently, each idiomatic and literal phrase was embedded in a sentence. Each sentence consisted of two clauses: the first clause always started with an agent (a name; e.g. Dolan ...), followed by the idiom / matched literal phrase in the past tense (e.g. ... spilled / cooked the beans ...), followed by a supporting context (e.g. ... when he mentioned the surprise party to his friend / before he started adding vegetables to the soup pot). Non-meaningful versions of each sentence were created by replacing one word in the sentence context with a semantically anomalous word of the same grammatical class, which made a meaningful interpretation of the sentence impossible (e.g. Dolan spilled the beans when he returned the surprise party to his friend / Dolan cooked the beans before he started adding duration to the soup pot).

Overall, there were a total of 216 experimental items counterbalanced over four experimental conditions: idiomatic meaningful, idiomatic non-meaningful, literal meaningful, literal non-meaningful. For an example of the experimental items for the idiom bear one's cross, see Table 1.

[Insert Table 1 here]

To create auditory versions of each experimental sentence, we recorded the 216 items in a sound-attenuated booth using an AKG C 420 III PP condenser microphone and a Marantz professional digital recorder. A native female speaker of North American English was asked to 
read out every sentence with a natural-sounding intonation, with the microphone positioned about $5 \mathrm{~cm}$ from her mouth. To keep prosodic differences between the recordings minimal, the speaker was instructed to use the same prosodic pattern for each sentence. Upon recording, the 216 auditory items were transferred to a computer and edited using Praat (version 5.3.44; Boersma \& Weenink, 2013) to ensure that sentence onset and offset were standardized. In order to make sure there were no significant differences in the average length of the experimental items, we compared the average sentence length of all auditory stimuli across the four conditions. A one-way ANOVA revealed no significant differences $[\mathrm{F}(3,212)=0.39, \mathrm{p}=0.76]$.

To determine the order in which the 216 auditory items were presented during the task, all items were randomized using a Latin square randomization (Edwards, 1951) with sentence type and meaningfulness as blocking factors, and were distributed evenly across two experimental lists (corresponding to VLPFC and vertex stimulation sites). Each list contained two items of any given idiom quadruplet. The same number of idiomatic and literal, as well as meaningful and non-meaningful, sentences occurred on each list. Finally, as a precautionary measure, we re-created both experimental lists with reversed item order, resulting in a total of four experimental lists. The order of stimulation site (VLPFC or vertex first) and list administration was counterbalanced across participants.

\subsection{TMS Protocol}

We used a standard virtual lesion rTMS protocol, compatible with established TMS safety guidelines (Wassermann, 1998). Repetitive trains of TMS at $1 \mathrm{~Hz}$ (600 in total) were delivered to the neural target area for about 10 minutes, which was expected to induce a transient decrease in corticospinal excitability and concurrent disruption of cognitive tasks associated with the stimulated brain region, lasting for about 10-15 minutes (Pascual-Leone, 1999; Rossi, Hallet, 
Rossini \& Pascual-Leone, 2009). In preparation for each testing session, before participants came to the lab, their brain scans were imported into Brain Sight 2 software (Rogue Research, Montreal, Canada) to determine the two sites of cortical stimulation (VLPFC/experimental, and vertex/ control), as well as the left hand motor area. Upon a participant's arrival at the laboratory, we performed MRI-to-head co-registration, using three anatomical landmarks on the head (tip of the nose, bridge of the nose, as well as superior lateral edge of the tragus of the left and right ear) whose position was assessed using an infrared tracking system (Polaris, Northern Digital, Waterloo, Canada). Upon successful co-registration, infrared tracking was used to monitor the position of the coil with respect to the participant's brain. For all stimulations, we used a 70mm figure-of-eight coil, driven by a high-speed magnetic stimulator that produced short duration biphasic pulses (Magstim Rapid 1400, Wales, U.K). The stimulator was controlled through Presentation software (Neurobehavioral Research), installed on a Dell Precision M 60 laptop, driven by an Intel ${ }^{\circledR}$ Core ${ }^{\text {TM }} 2$ CPU T 7600 processor.

To ascertain the maximal strength that could be used for the experimental stimulation, we determined the resting motor threshold (RMT) for each participant. Two EMG surface electrodes were placed over the first dorsal interosseus muscle of a participant's right hand. Single TMS pulses were then delivered to their left motor cortex hand area, with the TMS coil aligned tangentially to the skull and the coil's handle pointing posteriorly. Stimulation intensity and coil position were adjusted until the EMG electrodes recorded a signal greater than $50 \mu \mathrm{V}$ for a minimum of five trials out of ten.

After RMT was determined, the experimental stimulation began. The intensity level was set to $110 \%$ of the RMT value. As noted, rTMS stimulation was applied to the target site (VLPFC or vertex) in trains of 600 pulses at $1 \mathrm{~Hz}$. Five participants reported discomfort during 
rTMS stimulation to the VLPFC, caused by strong muscle twitches in the jaw. For these subjects, the intensity level was reduced accordingly.

Based on past work from our group, we estimated that rTMS stimulation at the frequency level we used should yield a 10 - 15 min inhibitory effect (see Boroojerdi, Prager, Muellbacher \& Cohen, 2000; Gerschlager, Siebner \& Rothwell, 2001; Shum, Shiller, Baum \& Gracco, 2011), which we determined to be sufficient to complete the idiom task. To confirm that participants indeed had enough time to finish the idiom task before any rTMS effects trailed off, we conducted a post-hoc analysis of the logfiles created for each experimental run. The mean completion time of the experimental task was 10.25 minutes across subjects and sessions $($ maximum $=11.25 \mathrm{~min} . ;$ minimum $=9.32 \mathrm{~min} . ; S D=0.44 \mathrm{~min})$.

Based on prior work (Pascual-Leone, 1999; Walsh \& Cowey, 2000), we expected that TMS should primarily slow a participant's reaction times, rather than lead to a decline in accuracy. However, past rTMS and tDCS studies on idiom comprehension consistently reported effects on accuracy (Rizzo et al., 2007; Fogliata et al., 2007; Sela et al., 2012), suggesting that rTMS not only slows cognitive performance, but also makes it more prone to errors. Thus, our expectation was somewhat open as to whether rTMS effects should arise for both reaction times and accuracy.

\subsection{Localization of Stimulation Sites}

For stimulation to the left VLPFC, we used the Montreal Neurological Institute (MNI) coordinates $(x=-54, y=21, z=12)$, corresponding to the left mid ventral prefrontal cortex or pars triangularis, BA 45 . We chose this site specifically because it has been reported to be maximally sensitive to distant semantic relationships in studies on semantic retrieval in the 
context of competing alternatives (Badre \& Wagner, 2007; Whitney, Kirk, O’Sullivan et al., 2011; Whitney et al., 2012).

For vertex-rTMS we used the MNI coordinates $x=0, y=-30, z=80$ (Ko et al., 2008) to guide rough coil placement, and then adjusted the stimulation sites individually for each participant, determining vertex as the highest point of the skull located medially between both hemispheres (Leitão, Thielscher, Werner, et al., 2012). The mean MNI coordinates for VertexrTMS across subjects were $[x=0.16, y=-23.37, z=80.19]$.

The cortical site for the left hand motor area was also determined individually for each participant, as the knob-like structure in the pre-central gyrus of the left hemisphere that is shaped like an omega in the axial plane and looks like a hook in the sagittal plane (see Yousry, Schmid, Alkadhi, et al., 1997). The mean MNI coordinates across subjects for the hand motor area were $[x=-35.08, y=-17.94, z=51.23]$.

\subsection{Simon Cognitive Control Task}

The Simon task is a computer-based interference task (for a review, see Lu \& Proctor, 1995), and is based on the observation that participants execute a motor response more quickly and more accurately if the response is spatially congruent to the stimulus location, even when stimulus location is not relevant to the task. The original Simon effect was obtained with auditory stimuli (Simon \& Small, 1969), but it has also been replicated with color as the relevant dimension (see Simon \& Berbaum, 1990; Zorzi \& Umiltá, 1995), as in the current adaptation.

Participants saw red and blue squares appear on the left or right side of a screen. Each trial started with a fixation cross, displayed for $500 \mathrm{~ms}$ at the centre of the computer monitor, followed by the appearance of the color square. When the square was blue, subjects were instructed to press a button on the left side of the keypad with their left hand. When the square 
was red, they were instructed to press a button on the right side with their right hand. The maximal response time was set to $1700 \mathrm{~ms}$. In congruent trials, the screen location of the square and the response side determined by the square color were identical, whereas in incongruent trials, they were not. Cognitive control load is proportionally greater in incongruent trials, since participants need to overcome the prepotent response to press the button on whichever side they saw the stimulus appear (Hommel, 1993).

We computed the mean correct response time for each participant in congruent and incongruent trials, excluding outliers that were more than 2 standard deviations from the mean (166 out of 3841 cells in total; $4.32 \%$ of all data points). Based on these values, we computed a cognitive control cost score for each participant, by subtracting the average reaction time on congruent trials (easy trials, i.e. low demand on cognitive control) from the average reaction time on incongruent trials (hard trials, i.e. high demand on cognitive control). Thus, a higher Simon cost score reflects a greater difference between hard and easy trials, and thus lower levels of cognitive control.

3. Results

We constructed linear mixed-effects (LME) models with random slopes where appropriate, as implemented in the lme4 library (Bates, 2005; Bates \& Sarkar, 2005) within R (R Development Core Team, 2009). The dependent variables were accuracy (a binomial factor), and correct reaction times (RT; in milliseconds), time-locked to the offset of the auditory sentence. The independent variables were sentence type (a categorical variable with two levels: Idiomatic versus Literal), site of stimulation (a categorical variable with two levels: stimulation to VLPFC and vertex), idiom familiarity (a scaled continuous variable based on prior ratings from Libben \& Titone, 2008), and the Simon cost score (a scaled continuous variable; see above). Because idiom 
familiarity and decomposability are correlated (Libben \& Titone, 2008; Titone \& Connine, 1994b), all models included idiom decomposability as a control factor. We used deviation coding for all omnibus models; model splits were treatment-coded (with vertex as the reference level for site of stimulation, and the literal condition as the reference level for sentence type). Accuracy and RT analyses reported below were conducted on meaningful items only. Five items out of 108 were excluded from the analysis, since they yielded abnormally long average reaction times (reaction times which were more than 2 standard deviations away from the mean for meaningful items). Table 2 displays the average RT and accuracy, as well as the standard errors, for meaningful items, split out by sentence type and site of stimulation.

[insert Table 2 here]

\subsubsection{Accuracy}

Stepwise log-likelihood model comparisons (Baayen, Davidson, \& Bates, 2008; Barr et al., 2013) showed that by-subject and by-item random slopes were not warranted for this model.

We found a significant main effect of sentence type $(b=-1.05, S E=0.28, z=-3.71)$, and a significant main effect of familiarity $(b=0.57, S E=0.15, z=3.82)$ in the omnibus accuracy model. In addition, there were trending towards significant interactions between sentence type and familiarity $(b=0.55, S E=0.28, z=1.94)$, and between familiarity and cognitive control $(b=-0.21, S E=0.12, z=-1.81)$. To investigate what was driving these interactions, we performed a model split in which we median-split items by cognitive control (as done below in the RT analyses). Thus, we computed two models, one for low-control individuals, and another one for high-control individuals. 
In both models, we found a significant main effect of sentence type (low-control individuals: $b=-1.24, S E=0.44, z=-2.81$; high-control individuals: $b=-1.24, S E=0.44, z=-$ 2.81), indicating that both low- and high-control individuals responded less accurately to idioms than to literal items. However, only the model for high-control individuals showed a significant main effect of familiarity $(b=0.81, S E=0.41, z=1.99)$, whereas the main effect of familiarity was not significant for low-control individuals $(b=0.02, S E=0.38, z=0.04)$. Thus, especially people with higher cognitive control capacity were sensitive to variations in idiom familiarity.

No other main effects or interactions reached significance in the omnibus accuracy model (main effect of site of stimulation: $b=-0.09, S E=0.22, t=-0.40$; main effect of cognitive control: $b=-0.01, S E=0.20, t=-0.05)$. Table 3 shows the statistical results for all model comparisons in the accuracy and reaction time LMER models.

\section{[Insert Figure 1 here]}

[Insert Table 3 here]

\subsubsection{Reaction Times}

Prior to analysis, the correct reaction time data were trimmed minimally through exclusion of outliers which were more than 2 standard deviations from the mean (resulting in an exclusion of 170 / 3454 data points, $4.9 \%$ of all observations; a justifiable rate according to Ratcliff, 1993). Log-likelihood model comparisons indicated that by-subject random slopes were warranted for sentence type and site of stimulation. By-item random slopes were not warranted for this model.

We found a significant four-way interaction among sentence type, site of stimulation, familiarity and cognitive control $(b=-92.0, S E=33.26, t=-2.77)$. To investigate what was 
driving this complex four-way interaction, we broke the interaction down by performing a median split by cognitive control. Thus, we computed two models, one model for low-control individuals, and one model for high-control individuals.

In examining the data for participants with low levels of cognitive control, analyses showed no significant main effects or interactions, despite patterns that may be gleaned from the left panel of Figure 2 (main effect of sentence type: $b=12.00, S E=55.67, t=0.22$; main effect of site of stimulation: $b=104.41, S E=82.37, t=1.27$; main effect of familiarity: $b=-15.12, S E$ $=28.63, t=-0.53$; three-way interaction between sentence type, site of stimulation and familiarity: $b=-79.55, S E=51.32, t=-1.55)$.

In contrast, the model for individuals with low levels of cognitive control showed a significant three-way interaction among sentence type, site of stimulation and idiom familiarity $(b=82.55, S E=43.02, t=1.96)$. To investigate the source of this three-way interaction, we performed another model split, in which we split items by familiarity. The results showed a significant interaction between sentence type and site of stimulation only in the model for lowfamiliar items $(b=-126.39, S E=62.85, t=-2.01)$, and not in the model for high-familiar items $(b=86.27, S E=56.80, t=1.50)$. Another split of the model for low-familiar items by sentence type showed that there was a significant main effect of site of stimulation only for idiomatic $(b=$ -122.37, $S E=56.95, t=-2.15)$ and not literal items $(b=7.54, S E=35.79, t=0.21)$.

Thus, when rTMS was applied to the VLPFC of high-control individuals, reaction times became faster for low-familiar idioms (in comparison the reaction times for low-familiar idioms during vertex stimulation). Figure 2 (right panel; high control individuals) picks up this pattern, and shows a decrease in RT for low-familiar idioms from vertex to VLPFC stimulation. 


\subsubsection{Summary}

Overall, the accuracy and RT data showed two things of interest. First, analysis of the accuracy rates suggested that particularly high- (and not low-) control individuals were susceptible to variations and idiom familiarity. Second, the reaction time data confirmed this pattern, and showed that in high-control individuals, there was a decrease in reaction times to low-familiar idioms when rTMS was applied to the VLPFC.

Taken together, these findings could suggest a speed-accuracy trade-off in high-control individuals: When stimulation was applied to the VLPFC, high-control individuals became faster for low-familiar idioms, but they also became less accurate.

[Insert Figure 2 here]

\section{Discussion}

Our main question of interest was whether an rTMS-induced 'artificial lesion' to the left VLPFC (specifically, BA 45) would lead to a comprehension disadvantage for idiomatic but not literal sentences. We hypothesized this neural region would be active during idiom comprehension because of its involvement in tasks that require the controlled selection among competing representations (Badre \& Wagner, 2002, 2007; Badre et al., 2005; Whitney, Kirk, O’Sullivan et al., 2011; Whitney et al., 2012). According to our hypothesis, such circumstances should apply to idioms because they have semantically conflicting literal and figurative meanings. Our expectation was that low-familiar idioms, in particular, should be prone to rTMSinduced disruptions, because these items involve a maximal semantic conflict between a less familiar figurative meaning and a proportionally more salient literal meaning. 
Indeed, our findings suggest that the VLPFC is crucial to the understanding of lowfamiliar idioms. Following stimulation to this neural target site, meaningfulness judgments to low-familiar idioms were significantly faster and also less accurate than responses to matched literal control phrases, particularly for individuals with high levels of cognitive control.

Interestingly, an rTMS-induced pattern of less accurate responses with faster reaction times has also been reported in previous studies on idiom comprehension. Rizzo et al. (2007), for example, found that, following rTMS stimulation to the left dorso-lateral PFC, study participants were faster but also produced more errors to idiomatic than to literal items. Since the Rizzo et al. (2007) study used a sentence-to-picture matching task where people had to choose the correct picture among a literal and idiomatic representation, the authors interpreted their findings as a 'release from inhibition'; suggesting that, as a consequence of rTMS stimulation, participants were less able to correctly inhibit the idiom's literal interpretation and more likely to choose the literal foil. Even though the experimental task of the present study involved no such overt presentation of the literal meaning as in the Rizzo et al. (2007) study, our use of low-familiar idioms could have lead to a similar behavioral response in participants. Low-familiar idioms involve a maximal semantic conflict between a less known figurative and more salient literal meaning, which normally needs to be resolved by the prefrontal cortex. As in the Rizzo et al. (2007) study, rTMS stimulation to this neural target area probably caused an impairment in PFClocated inhibitory circuits, which in turn lead to a drop in accuracy for low-familiar idioms.

The experimental finding that particularly low-familiar (and not high-familiar) idioms are subserved by prefrontal cortex circuits lends support to hybrid views of idiom comprehension, which argue that idioms are accessed through a network of interconnected nodes whose activation spreads sequentially within and between the component words (Titone \& Connine, 
1999; Titone \& Libben, 2014). Thus, the connection strength among individual constituents depends on the frequency with which the unit is activated (Jescheniak \& Levelt, 1994; Levelt, Roelofs, \& Meyer, 1999). For low-familiar idioms, this connection is most likely weaker than in high-familiar idioms, due to the lack of repeated activation for these less-frequently encountered items. Thus, because low-familiar idioms are less tightly bound as a unit, their literal constituent words should lead to greater interference during processing (Kan \& Thompson-Schill, 2004), requiring greater inhibitory capacity during processing. The co-activation of multiple meanings then calls on VLPFC-guided control mechanisms that maintain these meanings in a temporary loop, evaluate them against the sentence context, and finally select the figurative meaning by suppressing all unwanted literal representations.

This interpretation could also explain the absence of an idiom-specific effect in the one previous rTMS study that investigated the VLPFC (Oliveri et al., 2004). In that study, only highfamiliar idioms were used, i.e. items that likely involve very little interference from literal constituents, because their configurations are highly over-learned. Such circumstances should minimize controlled processing demands and, consequently, decrease VLPFC-input.

A previous EEG study supports this view (Rommers, Dijkstra, \&Bastiaansen, 2013), as it demonstrates that high-familiar idioms involve only minimal activation of literal constituent words. Rommers et al. (2013) analyzed the N400 EEG component (see Kutas \& Federmeier, 2009; for review) to index semantic integration difficulties that participants experienced when they were reading idiomatic and matched literal sentences for comprehension. The experimental sentences were modified in that idioms and matched literal phrases were preceded by a strong biasing context and key constituent words of the idiomatic or literal phrases were replaced with either semantically related or unrelated words (e.g. in the Dutch idiom tegen de lamp lopen, lit. 
to walk against the lamp, fig. to get caught; 'lamp' was replaced with 'candle' [related] or 'fish' [unrelated]). The results revealed that word substitutions in literal control sentences elicited a graded pattern of N400s, with related words eliciting a significantly smaller N400 than unrelated words, thus suggesting fewer integration difficulties when participants were reading contextually related rather than unrelated words. In high-familiar idioms, in contrast, there was no graded $\mathrm{N} 400$; that is, the brain response was the same to related and unrelated words. The authors argue that familiar idioms do not require compositional word-by-word processing in the way that literal language does, so that unrelated word substitutions in these expressions do not increase controlrelated processing demands. Thus, previously obtained evidence (Oliveri et al., 2004; Rommers et al., 2013) and the data from present investigation indicate that control-related processing demands increase (and involve VLPFC-input to a greater extent) when several semantic representations are maximally conflicting (such as in low-familiar idioms), whereas controlrelated demands are minimal when one representation is highly salient compared to the others (Oliveri et al., 2004; Rommers et al., 2013).

The present study indicates that the impairments in idiom comprehension upon prefrontal cortex stimulation were especially pronounced in high-control individuals. In particular, our data indicate a speed-accuracy trade-off for these individuals when rTMS was applied to the VLPFC. At vertex stimulation (Figure 1, right panel), high-control individuals were able to maintain a rather high accuracy for low-familiar items (see Figure 1, right panel), even though the prolonged RT data in this condition indicate that people had to work harder to maintain this high level of accuracy (Figure 2, right panel). rTMS stimulation to the VLPFC items then accelerated their response times for low-familiar idioms (compared to vertex; Figure 2, right panel), but it also lead to a drop in accuracy for these items (Figure 1, right panel). Interestingly then, the 
accuracy and RT profiles of high-control individuals under VLPFC stimulation look remarkably similar to the vertex profile of low-control individuals: high accuracy and fast response times to high-familiar idioms, but fast response times with low accuracy for low-familiar idioms.

The fact that only high-control individuals, and not low-control individuals, were affected by VLPFC stimulation, could indicate that high-control individuals may rely more on the integrity of VLPFC substrates during idiom processing, potentially in order to use controlled processing and suppress conflicting semantic representations. Support for this interpretation comes from several studies that have linked individual differences in executive functions to white and gray matter variations in the frontal cortex (Fornito, Yücel, Wood, et al., 2004; Forstmann, Jahfari, Scholte et al., 2008). For example, Forstmann et al. (2008) investigated axonal diameter, fiber density and coherence of white matter tracts in the frontal lobes of highand low-control individuals. The results showed that high-control individuals (as measured by the Simon task) have a stronger coherence in white matter tracts of the fronto-occipital fasciculus, a fiber tract that connects the lateral frontal cortex with more posterior brain regions, among them the temporal lobe. Importantly, this fiber tract has been implicated by several studies as the main sub-cortical pathway mediating semantic processing (the ventral stream; Duffau, Gatignol, Mandonnet et al., 2005; Saur, Kreher, Schnell, et al., 2008). The results of the present investigation are compatible with such findings; one could assume, for example, that idiom comprehension (and presumably the comprehension of semantic ambiguities in general; Boulenger, Hauk \& Pulvermüller, 2009) crucially relies on the VLPFC to balance and evaluate the conflicting meanings, and this process is additionally modulated through the integrity and strength of white matter tracts that ensure the quick and efficient information transfer from semantic storage sites in the temporal lobe and the frontal cortex. 
A remaining question is whether the role of the VLPFC is one specifically dedicated to idiom comprehension, or whether its role is a more general one, indexing increased workload or effortful processing for any instance of selection demands (Boulenger, Hauk \& Pulvermüller, 2009). Even though the present data indicate an idiom-specific effect (since there was no rTMS effect on literal items), to date there is more evidence in the extant literature to suggest that the role of the VLPFC in idiom comprehension is related to more general effortful processing circumstances, rather than to a specific brain response to idiomaticity. For example, VLPFCactivation has also been observed in lexical ambiguity resolution (Rodd, Davis \& Johnsrude, 2005) and the comprehension of semantically unexpected constituent words (Van Petten \& Luka, 2006). Thus, it seems that the activation or input of the VLPFC in the present study and in previous investigations may be best explained as a brain response to general instances of cognitive conflict or heavy burden on the language processing system (Boulenger, Hauk, \& Pulvermüller, 2009).

Finally, one limitation of the present study is that our data are unable to further dissociate the specific roles of the ventrolateral and the dorsolateral PFC during idiom comprehension. To date, studies have implicated both regions as crucial for idiom resolution: the VLPFC in the present investigation and in several fMRI studies (e.g. Rapp et al., Lauro et al., 2007), and the DLPFC in three previous rTMS studies (Fogliata et al., 2007; Rizzo et al., 2007; Sela et al., 2012). One possibility is a functional dissociation of these two neural regions with respect to idiom familiarity. For example, two previous rTMS studies addressing the dorsal PFC used exclusively high-familiar idioms (Fogliata et al., 2007; Rizzo et al., 2007; the third study did not control for this variable: Sela et al., 2012), whereas the ventral effect obtained in the present study emerged only for low-familiar idioms. Thus, a double dissociation is possible: the VLPFC 
is recruited for low-familiar idioms, the DLPFC is recruited for high-familiar idioms. We cannot entirely exclude such a possibility; even though it would raise the question why high-familiar idioms recruit PFC substrates in the first place, since the salient literal meaning of these items should induce very little interference during processing, and minimize controlled processing demands in the PFC. Thus, a next step for future rTMS and fMRI studies is to investigate both regions, and check whether neural activity in these regions is modulated by variables which are known to affect idiom processing: idiom familiarity, as in the present study, but also literal plausibility or degree of semantic overlap between the idiomatic meaning and the meanings of an idiom's constituent words.

\section{Conclusion}

To date, investigations of the role of the ventro-lateral prefrontal cortex (VLPFC) in idiom processing have been equivocal, with fMRI studies consistently demonstrating its involvement (Zempleni et al., 2007; Lauro et al., 2008; for reviews see Rapp et al., 2012; Bohrn et al., 2012), and rTMS studies failing to corroborate this result (Oliveri et al., 2004).

The present investigation used a meaningfulness judgment task to test whether rTMS stimulation to the VLPFC and a control site (vertex) differentially affects the comprehension of idiomatic and matched literal sentences. Our prediction was that rTMS should disrupt the comprehension of low-familiar idioms, in particular, as these items involve a maximal semantic conflict between a less known figurative and a more salient literal interpretation.

The results corroborated this hypothesis, but individual differences in cognitive control capacity modulated the effect: Only high-control individuals were susceptible to rTMS-induced disruptions, indicating that these people relied more on VLPFC integrity during idiom comprehension. 
In sum, the present data show that idiom resolution is predicted by both idiom-inherent and listener- or speaker-related characteristics, which supports hybrid or constraint-based views of idiom processing (Titone \& Libben, 2014). In addition, the findings presented in this study support the notion that cognitive control modulates idiom performance primarily under compromised processing circumstances (Papagno et al., 2003; Rassiga et al., 2009), but not when processing is unimpaired (Columbus et al., 2015).

Future studies need to disentangle the potentially diverging roles of the dorsolateral (DLPFC) and ventrolateral PFC (VLPFC) during idiom processing, and illustrate how general cognitive functions (such as cognitive control) interact with idiom-specific factors other than familiarity (for example, decomposability or literal plausibility) in constraining idiom resolution. 
Table 1

Experimental items for the four sentence conditions: idiomatic/literal meaningful, idiomatic/literal non-meaningful.

Idiomatic - Meaningful Josh bore his cross the entire flight and didn't complain about the snoring man.

Literal - Meaningful Josh lost his cross when he dropped it in the grass on the way home from church.

Idiomatic - Not Meaningful Josh bore his cross the entire flight and didn't stockpile about the snoring man.

Literal - Not Meaningful Josh lost his cross when he dropped it in the stork on the way home from church. 


\section{Table 2}

Means and standard errors (subject-weighted) in idiomatic and literal sentences for correct reaction times (in ms) and percentage of accuracy, depending on site of stimulation.

\begin{tabular}{ccccccc}
\hline & \multicolumn{2}{c}{ Correct Reaction Times } & & \multicolumn{2}{c}{ Accuracy } \\
\cline { 2 - 3 } & $M$ & $S E$ & & $M$ & $S E$ \\
\hline Baseline/Vertex & & & & & \\
Idiomatic & 501.21 & 53.16 & & 0.88 & 0.02 \\
Literal & 445.32 & 38.80 & & 0.93 & 0.01 \\
\hline Ventro-Lateral PFC & & & & \\
Idiomatic & 547.32 & 55.10 & & 0.86 & 0.02 \\
Literal & 493.43 & 40.87 & & 0.92 & 0.01 \\
\hline
\end{tabular}


Table 3

Linear mixed effects regression results for the deviation-coded four-factor model, including sentence type, site of stimulation, idiom familiarity and Simon cognitive control cost score.

\begin{tabular}{|c|c|c|c|c|c|c|}
\hline \multirow[b]{2}{*}{ Fixed Effects } & \multicolumn{3}{|c|}{ Correct Reaction Times } & \multicolumn{3}{|c|}{ Accuracy } \\
\hline & $b$ & $S E$ & $t$ & $b$ & $S E$ & $z$ \\
\hline Sentence Type & 0.77 & 0.46 & 1.67 & -0.74 & 0.17 & -4.39 \\
\hline Site of Stimulation & 0.90 & 0.76 & 1.19 & -0.18 & 0.12 & -1.46 \\
\hline Idiom Familiarity (scaled) & -0.12 & 0.24 & -0.49 & 0.20 & 0.11 & 1.85 \\
\hline Simon Cost Score (scaled) & -0.23 & 0.88 & -0.26 & 0.06 & 0.14 & 0.43 \\
\hline Sentence Type * Site of Stimulation & -0.22 & 0.52 & -0.42 & -0.03 & 0.25 & -0.14 \\
\hline Sentence Type * Idiom Familiarity & -0.33 & 0.39 & -0.85 & 0.36 & 0.17 & 2.12 \\
\hline Site of Stimulation * Idiom Familiarity & -0.03 & 0.26 & -0.12 & 0.05 & 0.12 & 0.43 \\
\hline Sentence Type $*$ Simon Cost Score & -0.29 & 0.36 & -0.81 & 0.05 & 0.14 & 0.33 \\
\hline Site of Stimulation * Simon Cost Score & 1.91 & 0.77 & 2.49 & 0.02 & 0.14 & 0.15 \\
\hline Idiom Familiarity * Simon Cost Score & 0.09 & 0.13 & 0.66 & -0.08 & 0.08 & -0.98 \\
\hline Sentence Type * Site of Stimulation * Idiom Familiarity & -0.31 & 0.52 & -0.61 & -0.04 & 0.25 & -0.16 \\
\hline Sentence Type * Site of Stimulation * Simon Cost Score & -0.19 & 0.52 & -0.38 & 0.09 & 0.28 & 0.33 \\
\hline Sentence Type * Idiom Familiarity * Simon Cost Score & -0.30 & 0.26 & -1.16 & 0.06 & 0.14 & 0.43 \\
\hline Site of Stimulation * Idiom Familiarity * Simon Cost Score & 0.11 & 0.26 & 0.43 & -0.14 & 0.14 & -1.01 \\
\hline Sentence Type * Site of stimulation * Idiom Familiarity * Simon Cost Score & -1.12 & 0.52 & -2.18 & -0.02 & 0.28 & -0.07 \\
\hline
\end{tabular}




\begin{tabular}{|c|c|c|c|c|c|c|}
\hline Control Predictors & $b$ & $S E$ & $t$ & $b$ & $S E$ & $z$ \\
\hline Meaningfulness & -0.18 & 0.26 & -0.71 & 0.01 & 0.12 & 0.09 \\
\hline Idiom decomposability (scaled) & 0.21 & 0.24 & 0.87 & 0.09 & 0.10 & 0.89 \\
\hline Random Effects & \multicolumn{3}{|c|}{ Variance } & \multicolumn{3}{|c|}{ Variance } \\
\hline Subject & \multicolumn{3}{|c|}{11.76} & \multicolumn{3}{|c|}{0.22} \\
\hline Subject | Sentence Type & \multicolumn{3}{|c|}{0.98} & \multicolumn{3}{|c|}{$n / a$} \\
\hline Subject | Site of Stimulation & \multicolumn{3}{|c|}{8.19} & \multicolumn{3}{|c|}{$n / a$} \\
\hline Subject | Idiom Familiarity & \multicolumn{3}{|c|}{$n / a$} & \multicolumn{3}{|c|}{0.03} \\
\hline Item & \multicolumn{3}{|c|}{1.67} & \multicolumn{3}{|c|}{0.52} \\
\hline Item | Sentence Type & \multicolumn{3}{|c|}{4.73} & \multicolumn{3}{|c|}{0.65} \\
\hline
\end{tabular}




\section{Figure 1}

Mean accuracy for meaningful idiomatic and literal sentences following stimulation to vertex (left panel) and ventrolateral PFC (right panel), depending on idiom familiarity and individual levels of cognitive control. Error bars indicate standard errors of the mean (subject-weighted).
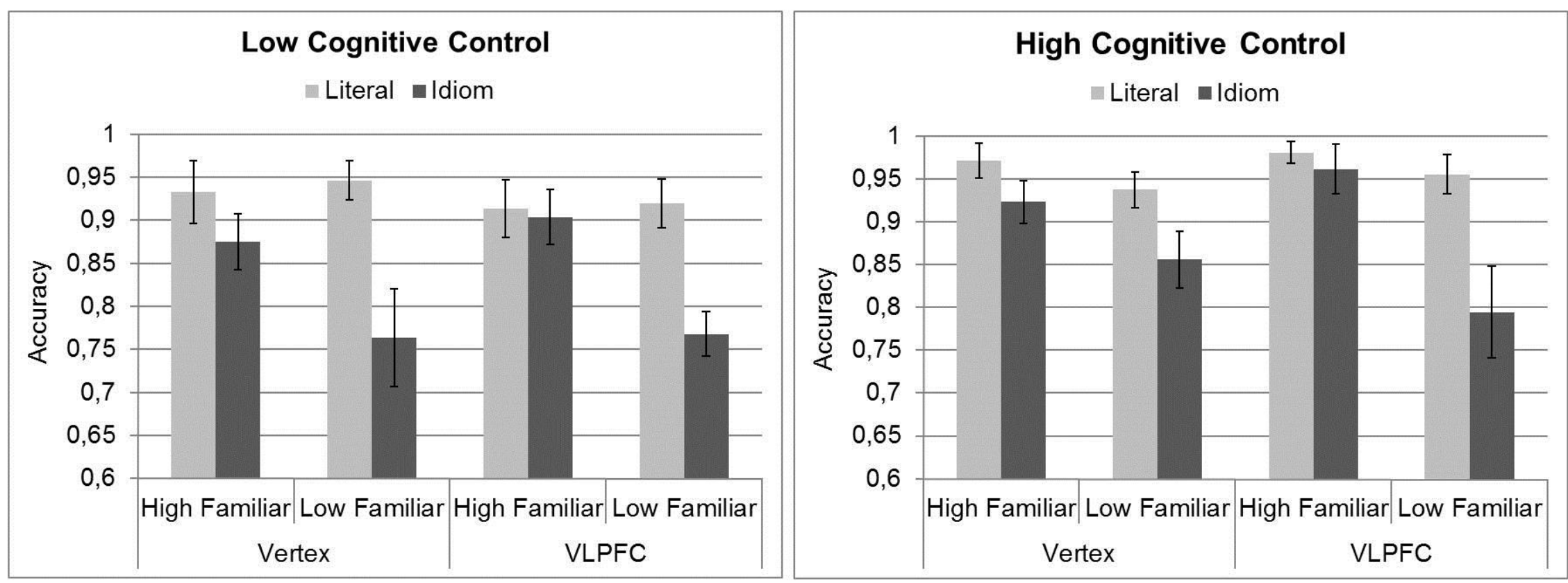


\section{Figure 2}

Mean correct reaction times ( \pm standard errors of the mean, subject-weighted) for meaningful items, after stimulation to vertex (left panel) and ventrolateral PFC (right panel), depending on sentence type, idiom familiarity and individual levels of cognitive control.
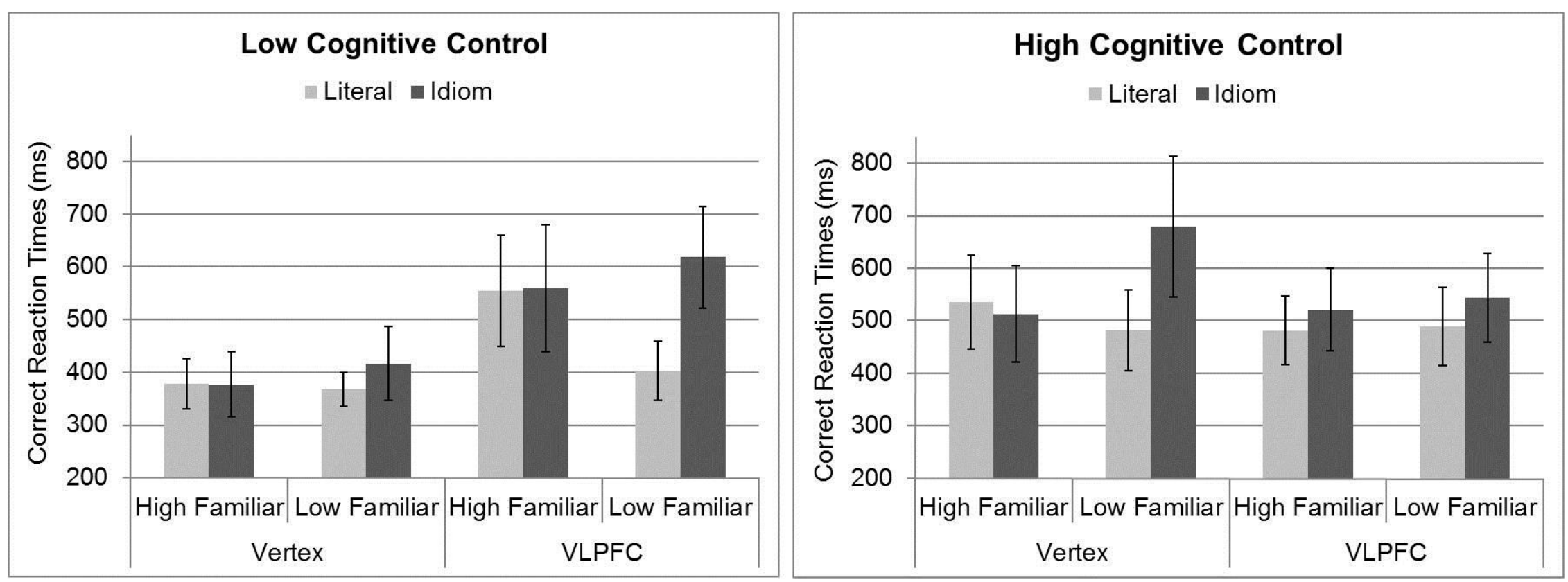
Conflicts of interest:

None declared. 


\section{Bibliography}

Aron, A. (2007). The neural basis of inhibition in cognitive control. Neuroscientist, 13, 214-228.

Aron, A., Robbins, T., \& Poldrack, R. (2004). Inhibition and the right inferior frontal cortex. TRENDS in Cognitive Sciences, 8, 170-177.

Awh, E., Jonides, J., Smith, E., Schumacher, E., Koeppe, R., \& Katz, S. (1996). Dissociation of storage and rehearsal in verbal working memory: Evidence from positron emission tomography. Psychological Science, 7, 25-31.

Baayen, R. H., Davidson, D. J., \& Bates, D. M. (2008). Mixed-effects modeling with crossed random effects for subjects and items. Journal of Memory and Language, 59, 390-412.

Baayen, R. H., \& Milin, P. (2010). Analyzing reaction times. International Journal of Psychological Research, 3, 12-28.

Baddeley, A., \& Della Salla, S. (1996). Working memory and executive control. Philosophical Transactions: Biological Sciences, 351, 1397-1404.

Badre, D. (2008). Cognitive control, hierarchy, and the rostro-caudal organization of the frontal lobes. TRENDS in Cognitive Sciences, 12, 193-200.

Badre, D., Poldrack, R., Pare-Blagoev, E., Insler, R., \& Wagner, D. (2005). Dissociable controlled retrieval and generalized selection mechanisms in ventrolateral prefrontal cortex. Neuron, 47, 907-918.

Badre, D., \& Wagner, A. (2002). Semantic retrieval, mnemonic control, and prefrontal cortex. Behavioral and Cognitive Neuroscience Reviews, 1, 206-218.

Badre, D., \& Wagner, A. (2007). Left ventrolateral prefrontal cortex and the cognitive control of memory. Neuropsychologia, 45, 2883-2901. 
Barr, D., Levy, R., Scheepers, C., \& Tily, H. (2013). Random effects structure for confirmatory hypothesis testing: Keep it maximal. Journal of Memory and Language, 68, 255-278.

Bates, D. (2005). Fitting linear mixed models in R. R News, 5, 27-30.

Bates, D., \& Sarkar, D. (2005). The lme4 library. On-line available: http://lib. stat. cmu. edu/R/CRAN.

Bates, D., \& Sarkar, D. (2007). Lme4: Linear mixed-effects models using S4 classes. R package version 0.9975-12. URL http://CRAN.R-project.org/.

Beeman, M., Friedman, R., Grafman, J., Perez, E., Diamond, S., \& Lindsay, M. (1994). Summation priming and coarse semantic coding in the right hemisphere. Journal of Cognitive Neuroscience, 6, 26-45.

Bialystok, E., Craik, F. I., Klein, R., \& Viswanathan, M. (2004). Bilingualism, aging, and cognitive control: Evidence from the Simon task. Psychology and Aging, 19, 290-303.

Blumenfeld, H., \& Marian, V. (2011). Bilingualism influences inhibitory control in auditory comprehension. Cognition, 118, 245-57.

Bobrow, S., \& Bell, S. (1973). On catching on to idiomatic expressions. Memory \& Cognition, 1, 343-346.

Boersma, P., \& Weenink, D. (2013). Praat: Doing phonetics by computer (version 5.3. 60).

Bohrn, I., Altmann., U., \& Jacobs, A. (2012). Looking at the brains behind figurative language: A quantitative meta-analysis of neuroimaging studies on metaphor, idiom, and irony processing. Neuropsychologia, 50, 2669-2683.

Boroojerdi, B., Prager, A., Muellbacher, W., \& Cohen, L. (2000). Reduction of human visual cortex excitability using 1-Hz transcranial magnetic stimulation. Neurology, 54, 15291531. 
Botvinick, M., Braver, T., Barch, D., Carter, C., \& Cohen, J. (2001). Conflict monitoring and cognitive control. Psychological Review, 108, 624-652.

Boulenger, V., Hauk, O., \& Pulvermüller, F. (2009). Grasping ideas with the motor system: Semantic somatotopy in idiom comprehension. Cerebral Cortex, 19, 1905-1914.

Braver, T. (2012). The variable nature of cognitive control: A dual-mechanisms framework. TRENDS in Cognitive Sciences, 16, 106-113.

Braver, T., \& Barch, D. (2002). A theory of cognitive control, aging cognition, and neuromodulation. Neuroscience and Biobehavioral Reviews, 26, 809-817.

Braver, T., Barch, D., Keys, B., Carter, C., Kaye, J., Janowsky, J., Taylor, S., Yesavage, J., Mumenthaler, M., Jagust, W., Reed, B. (2001). Context processing in older adults: Evidence for theory relating cognitive control to neurobiology in healthy aging. Journal of Experimental Psychology: General, 130, 746-763.

Braver, T., Paxton, J., Locke, H., \& Barch, D. (2009). Flexible neural mechanisms of cognitive control within human prefrontal cortex. Proceedings of the National Academy of Sciences of the United States of America, 106, 7351-7356.

Braver, T., \& West, R. (2008). Working memory, executive processes and aging. In F. Craik \& T. Salthouse (Eds.), The handbook of aging and cognition (pp. 311-372). New York: Psychology Press.

Brownell, H., Simpson, T., Bihrle, A., Potter, H., \& Gardner, H. (1990). Appreciation of metaphoric alternative word meanings by left and right brain-damaged patients. Neuropsychologia, 28, 375-383.

Burke, D. M., \& Shafto, M. A. (2008). Language and aging. In F. Craik \& T. Salthouse (Eds.), The handbook of aging and cognition (pp. 373-443). New York: Psychology Press. 
Cacciari, C., \& Glucksberg, S. (1991). Understanding idiomatic expressions: The contribution of word meanings. Advances in Psychology, 77, 217-240.

Cacciari, C., \& Papagno, P. (2012). Neuropsychological and neurophysiological correlates of idiom understanding: How many hemispheres are involved? In M. Faust (Ed.), The Handbook of the Neuropsychology of Language, 2, (pp. 368-387). New Jersey: WileyBlackwell.

Cacciari, C., \& Tabossi, P. (1988). The comprehension of idioms. Journal of Memory and Language, 27, 668-683.

Caillies, S., \& Butcher, K. (2007). Processing of idiomatic expressions: Evidence for a new hybrid view. Metaphor \& Symbol, 22, 79-108.

Caillies, S., \& Le Sourn-Bissaoui, S. (2013). Nondecomposable idiom understanding in children: Recursive theory of mind and working memory. Canadian Journal of Experimental Psychology, 67, 108-116.

Caplan, D., Stanczak, L., \& Waters, G. (2008). Syntactic and thematic constraint effects on blood oxygenation level dependent signal correlates of comprehension of relative clauses. Journal of Cognitive Neuroscience, 20, 643-656.

Carpenter, P., Miyake, A., \& Just, M. (1994). Working memory constraints in comprehension: Evidence from individual differences in aphasia and aging. In M. Gernsbacher (Ed.), Handbook of Psycholinguistics (pp. 1075-1122). New York, NY: Academic Press.

Cieślicka, A., Heredia, R., \& Olivares, M. (2014). It's All in the Eyes: How language dominance, salience, and context affect eye movements during idiomatic language processing. In M. Pawlak \& L. Aronin (Eds.), Essential Topics in Applied Linguistics and Multilingualism (pp. 21-41). London, UK: Springer International Publishing. 
Colcombe, S., \& Kramer, A. F. (2003). Fitness effects on the cognitive function of older adults a meta-analytic study. Psychological Science, 14, 125-130.

Colombo, L. (1993). The comprehension of ambiguous idioms in context. In C. Cacciari, \& P. Tabossi (Eds.), Idioms: Processing, Structure, and Interpretation (pp. 163-200). New York, NY: Lawrence Erlbaum Associates.

Columbus, G., Sheikh N., Cote-Lecaldare, M., Häuser, K., Baum, S. \& Titone, D. (2015). Individual Differences in Executive Control Relate to Metaphor Processing: An Eye Movement Study of Sentence Reading. Frontiers in Human Neuroscience, 8, 1057.

Conner, P., Hyun, J., O’Connor Wells, B., Anema, I., Goral, M., Monereau-Merry, M., Rubino, D., Kuckuk, R., \& Obler, L. (2011). Age-related differences in idiom production in adultdhood. Clinical Linguistics and Phonetics, 25, 899-912.

Cronk, B. C., \& Schweigert, W. A. (1992). The comprehension of idioms: The effects of familiarity, literalness, and usage. Applied Psycholinguistics, 13, 131-146.

Daneman, M., \& Carpenter, P. (1980). Individual differences in working memory and reading. Journal of Verbal Learning and Verbal Behavior, 19, 450-466.

Devlin, J., \& Watkins, K. (2007). Stimulating language: Insights from TMS. Brain, 130, 610622.

Drag, L. L., \& Bieliauskas, L. A. (2010). Contemporary review 2009: cognitive aging. Journal of Geriatric Psychiatry and Neurology, 23, 75-93.

Duffau, H., Gatignol, P., Mandonnet, E., Peruzzi, P., Tzourio-Mazoyer, N., \& Capelle, L. (2005). New insights into the anatomo-functional connectivity of the semantic system: a study using cortico-subcortical electrostimulations. Brain, 128, 797-810. 
Duffy, S., Morris, R., \& Rayner, K. (1988). Lexical ambiguity and fixation times in reading. Journal of Memory and Language, 27, 429-446.

Duncan, J. (2001). An adaptive coding model of neural function in prefrontal cortex. Nature Reviews Neuroscience, 2, 820-829.

Edwards, A. (1951). Balanced latin-square designs in psychological research. The American Journal of Psychology, 598-603.

Embick, D., Marantz, A., Miyashita, Y., O’Neill, W., \& Sakai, K. (2000). A syntactic specialization for Broca's area. Proceedings of the National Academy of Sciences of the United States of America, 97, 6150-6154.

Engle, R. (2002). Working memory capacity as executive attention. Current Directions in Psychological Science, 11, 19-23.

Estill, R., \& Kemper, S. (1982). Interpreting idioms. Journal of Psycholinguistic Research, 11, $559-568$.

Faust, M., \& Balota, D. (1997). Inhibition of return and visuospatial attention in healthy older adults and individuals with dementia of the Alzheimer type. Neuropsychology, 11, 13-29.

Faust, M., Balota, D., Duchek, J., Gernsbacher, M., \& Smith, S. (1997). Inhibitory control during sentence comprehension in individuals with dementia of the Alzheimer type. Brain \& Language, 57, 225-253.

Fiez, J. (1997). Phonology, semantics, and the role of the left inferior prefrontal cortex. Human Brain Mapping, 5, 79-83.

Fogliata, A., Rizzo, S., Reati, F., Miniussi, C., Oliveri, M., \& Papagno, C. (2007). The time course of idiom processing. Neuropsychologia, 45, 3215-3222. 
Forstmann, B. U., Jahfari, S., Scholte, H. S., Wolfensteller, U., van den Wildenberg, W. P., \& Ridderinkhof, K. R. (2008). Function and structure of the right inferior frontal cortex predict individual differences in response inhibition: a model-based approach. The Journal of Neuroscience, 28, 9790-9796.

Frazier, L., Pacht, J., \& Rayner, K. (1999). Taking on semantic commitments, II: Collective versus distributive readings. Cognition, 70, 87-104.

Frazier, L., \& Rayner, K. (1990). Taking on to semantic commitments: Processing multiple meanings vs. multiple senses. Journal of Memory and Language, 29, 181-200.

Friederici, A., Fiebach, C., Schlesewksy, M., Bornkessel, I., \& von Cramon, D. (2006). Processing linguistic complexity and grammaticality in the left frontal cortex. Cerebral Cortex, 16, 1709-1717.

Frisson, S., \& Pickering, M. (1999). The processing of metonymy: Evidence from eye movements. Journal of Experimental Psychology: Learning, Memory, and Cognition, 25, 1366-1383.

Fornito, A., Yücel, M., Patti, J., Wood, S. J., \& Pantelis, C. (2009). Mapping grey matter reductions in schizophrenia: an anatomical likelihood estimation analysis of voxel-based morphometry studies. Schizophrenia Research, 108, 104-113.

Gabrieli, J., Poldrack, R., \& Desmond, J. (1998). The role of left prefrontal cortex in language and memory. Proceedings of the National Academy of Sciences of the United States of America, 95, 906-913.

Galinsky, A., \& Glucksberg, S. (2000). Inhibition of the literal: Metaphors and idioms as judgmental primes. Social Cognition, 18, 35-54. 
Gandiga, P., Hummel, F., \& Cohen, L. (2006). Transcranial DC stimulation (tDCS): A tool for double-blind sham-controlled clinical studies in brain stimulation. Clinical Neurophysiology, 117, 845-850.

Gerschlager, W., Siebner, H., \& Rothwell, J. (2001). Decreased corticospinal excitability after subthreshold $1 \mathrm{~Hz}$ rTMS over lateral premotor cortex. Neurology, 57, 449-455.

Gibbs, R. (1980). Spilling the beans on understanding and memory for idioms in conversation. Memory \& Cognition, 8, 149-156.

Gibbs, R. (1986). Skating on thin ice: Literal meaning and understanding idioms in conversations. Discourse Processses, 9, 17-30.

Gibbs, R., Bogdanovich, J., Sykes, J., \& Barr, D. (1997). Metaphor in idiom comprehension. Journal of Memory and Language, 37, 141-154.

Gibbs, R., Nayak, N., \& Cutting, C. (1989). How to kick the bucket and not decompose: Analyzability and idiom processing. Journal of Memory \& Language, 28, 576-593.

Gibbs, R., \& O’Brien, J. (1990). Idioms and mental imagery: The metaphorical motivation for idiomatic meaning. Cognition, 36, 35-68.

Glucksberg, S. (2001). Understanding figurative language: From metaphors to idioms. Oxford University Press.

Glucksberg, S., Brown, M., \& McGlone, M. S. (1993). Conceptual metaphors are not automatically accessed during idiom comprehension. Memory \& Cognition, 21, 711-719.

Glucksberg, S., Gildea, P., Bookin, H. (1982). On understanding nonliteral speech: Can people ignore metaphors? Journal of Verbal Learning and Verbal Behavior, 21, 85-98.

Glucksberg, S., \& McGlone, M. S. (1999). When love is not a journey: What metaphors mean. Journal of Pragmatics, 31, 1541-1558. 
Glucksberg, S., Newsome, M., \& Goldvarg, Yevgeniya. (2001). Inhibition of the literal: Filtering metaphor-irrelevant information during metaphor comprehension. Metaphor and Symbol, $16,277-298$.

Goldman-Rakic, P. (1995). Cellular basis of working memory. Neuron, 14, 477-485.

Goral, M., Spiro, I. I. I., Albert, M. L., Obler, L. K., \& Connor, L. T. (2007). Change in lexical retrieval skills in adulthood. The Mental Lexicon, 2, 215-238.

Greenwood, P. (2007). Functional plasticity in cognitive aging: Review and hypothesis. Neuropsychology, 21, 657-673.

Grodzinksy, Y. (2000). The neurology of syntax: Language use without Broca's area. Behavioral and Brain Sciences, 23, 1-71.

Häuser, K., Baum, S., \& Titone, D. (2015). Late L2 acquisition facilitates idiom processing in the L1: An eye movement study of idioms presented in a canonical vs non-canonical form. Poster presented at the Montreal Bilingual Brain Initiative Symposium: Multiple Perspectives on Bilingualism and the Brain, Montreal, Quebec.

Halford, G., Wilson, W., \& Phillips, S. (1998). Processing capacity defined by relational complexity: Implications for comparative, developmental, and cognitive psychology. Behavioral and Brain Sciences, 21, 803-831.

Hallet, P. (1978). Primary and secondary saccades to goals defined by instructions. Vision Research, 18, 1279-1296.

Hamblin, J., \& Gibbs, R. (1999). Why you can't kick the bucket as you slowly die: Verbs in idiom comprehension. Journal of Psycholinguistic Research, 28, 25-39. 
Hargreaves, I. S., Pexman, P. M., Pittman, D. J., \& Goodyear, B. G. (2011). Tolerating ambiguity: ambiguous words recruit the left inferior frontal gyrus in absence of a behavioral effect. Experimental Psychology, 58, 19-30.

Hasher, L., \& Zacks, R. (1988). Working memory, comprehension, and aging: A review and a new view. The Psychology of Learning and Motivation, 22, 193-225.

Hedden, T., \& Gabrieli, J. (2004). Insights into the ageing mind: A view from cognitive neuroscience. Nature Reviews Neuroscience, 5, 87-96.

Herwig, U., Satrapi, P., \& Schönfeldt-Lecuona, C. (2003). Using the nternational 10-20 EEG system for positioning of Transcranial Magnetic Stimulation. Brain Topography, 16, 9599.

Hilchey, M. D., \& Klein, R. M. (2011). Are there bilingual advantages on nonlinguistic interference tasks? Implications for the plasticity of executive control processes. Psychonomic Bulletin \& Review, 18, 625-658.

Hillert, D., \& Buračas, G. (2009). The neural substrates of spoken idiom comprehension. Language and Cognitive Processes, 24, 1370-1391.

Holsinger, E. (2013). Representing idioms: Syntactic and contextual effects on idiom processing. Language and Speech, 56, 373-394.

Hommel, B. (1993). The relationship between stimulus processing and response selection in the Simon task: Evidence for a temporal overlap. Psychological Research, 55, 280-290.

Hung, P., \& Nippold, M. (2014). Idiom understanding in adulthood: Examining age-related differences. Clinical Linguistics \& Phonetics, 28, 208-221.

Hussey, E., \& Novick, J. (2012). The benefits of executive control training and the implications for language processing. Frontiers in Psychology, 3, 1-14. 
Hutton, S., \& Ettinger, U. (2006). The antisaccade task as a research tool in psychopathology: A critical review. Psychophysiology, 43, 302-313.

Hyun, J., Conner, P. S., \& Obler, L. K. (2014). Idiom properties influencing idiom production in younger and older adults. The Mental Lexicon, 9, 294-315.

Iakimova, G., Passerieux, C., Denhiere, G., Laurent, J., Vistoli, D., Vilain, J., \& Hardy-Bayle, M. (2010). The influence of idiomatic salience during the comprehension of ambiguous idioms by patients with schizophrenia. Psychiatry Research, 177, 46-54.

Inhoff, A., \& Rayner, K. (1986). Parafoveal word processing during eye fixations in reading: Effects of word frequency. Perception \& Psychophysics, 40, 431-439.

Jahanshahi, M., Profice, P., Brown, R. G., Ridding, M. C., Dirnberger, G., \& Rothwell, J. C. (1998). The effects of transcranial magnetic stimulation over the dorsolateral prefrontal cortex on suppression of habitual counting during random number generation. Brain, 121, $1533-1544$.

Jefferies, E. (2013). The neural basis of semantic cognition: Converging evidence from neuropsychology, neuroimaging and TMS. Cortex, 49, 611-625.

Jescheniak, J. D., \& Levelt, W. J. (1994). Word frequency effects in speech production: Retrieval of syntactic information and of phonological form. Journal of Experimental Psychology: Learning, Memory, and Cognition, 20, 824-843.

Just, M., Carpenter, P., Keller, T., Eddy, W., \& Thulborn, K. (1996). Brain activation modulated by sentence comprehension. Science, $274,114-116$.

Kaan, E., \& Swaab, T. (2002). The brain circuitry of syntactic comprehension. TRENDS in Cognitive Sciences, 6, 350-356. 
Kan, I., \& Thompson-Schill, S. (2004). Selection from perceptual and conceptual representations. Cognitive, Affective, \& Behavioral Neuroscience, 4, 466-482.

Kane, M., Hasher, L., Stoltzfus, E., Zacks, R., \& Connelly, S. (1994). Inhibitory attentional mechanisms and aging. Psychology and Aging, 9, 103-112.

Kaufman, L. D., Pratt, J., Levine, B., \& Black, S. E. (2010). Antisaccades: a probe into the dorsolateral prefrontal cortex in Alzheimer's disease. A critical review. Journal of Alzheimer's Disease, 19, 781-793.

Kempler, D., Van Lancker, D., Marchman, V., \& Bates, E. (1999). Idiom comprehension in children and adults with unilateral brain damage. Developmental Neuropsychology, 15, 327-349.

Kintsch, W. (2000). Metaphor comprehension: A computational theory. Psychonomic Bulletin \& Review, 7, 257-266.

Kliegl, R., Grabner, E., Rolfs, M., \& Engbert, R. (2004). Length, frequency, and predictability effects of words on eye movements in reading. European Journal of Cognitive Psychology, 16, 262-228.

Ko, J., Monchi, O., Ptito, A., Bloomfield, P., Houle, S., \& Strafella, A. (2008). Theta burst stimulation-induced inhibition of dorsolateral prefrontal cortex reveals hemispheric asymmetry in striatal dopamine release during a set-shifting task-a TMS-[11C] raclopride PET study. European Journal of Neuroscience, 28, 2147-2155.

Koechlin, E., Ody, C., \& Kouneiher, F. (2003). The architecture of cognitive control in the human prefrontal cortex. Science, 14, 1181-1185. 
Kramer, A., Humphrey, D., Larish, J., Logan, G., Strayer, D. (1994). Aging and inhibition: Beyond a unitary view of inhibitory processing in attention. Psychology and Aging, 9, 491-512.

Langlotz, A. (2006). Idiomatic creativity: A cognitive-linguistic model of idiom-representation and idiom-variation in English. John Benjamins Publishing.

Lauro, L., Tettamanti, M., Cappa, S., \& Papagno, C. (2008). Idiom comprehension: A prefrontal task? Cerebral Cortex, 18, 162-170.

Lavidor, M. (2012). Mechanisms of hemispheric specialization: Insights from transcranial magnetic stimulation (TMS) studies. In M. Faust (Ed.), The Handbook of the Neuropsychology of Language, 2, (pp. 41-59). New Jersey: Wiley-Blackwell.

Leitão, J., Thielscher, A., Werner, S., Pohmann, R., \& Noppeney, U. (2012). Effects of Parietal TMS on Visual and Auditory Processing at the Primary Cortical Level-A Concurrent TMS-fMRI Study. Cerebral Cortex, 78.

Levelt, W., Roelofs, A., \& Meyer, A. (1999). A theory of lexical access in speech production. Behavioral and Brain Sciences, 22, 1-75.

Libben, M., \& Titone, D. (2008). The multidetermined nature of idiom processing. Memory \& Cognition, 36, 1103-1121.

Lu, C., \& Proctor, R. (1995). The influence of irrelevant location information on performance: A review of the Simon and spatial Stroop effects. Psychonomic Bulletin \& Review, 2, 174207.

Lustig, C., Hasher, L., \& Zacks, R. T. (2007). Inhibitory deficit theory: Recent developments in a “new view". In D. Gorfein \& C. MacLeod (Eds.), Inhibition in cognition. American Psychological Association. 
MacDonald, M. C., \& Christiansen, M. H. (2002). Reassessing working memory: comment on Just and Carpenter (1992) and Waters and Caplan (1996). Psychological Review, 109, 3554.

MacDonald, A., Cohen, J., Stenger, V., \& Carter, C. (2000). Dissociating the role of the dorsolateral prefrontal and anterior cingulate cortex in cognitive control. Science, 288, 1835-1838.

Madden, D. J. (1988). Adult age differences in the effects of sentence context and stimulus degradation during visual word recognition. Psychology and Aging, 3, 167-172.

Marian, V., Blumenfeld, H., \& Kaushanskaya, M. (2007). The language experience and proficiency questionnaire (LEAP-Q): Assessing language profiles in bilinguals and multilinguals. Journal of Speech, Language, and Hearing Research, 50, 940-967.

Mashal, N., Faust, M., Hendler, T., \& Jung-Beeman, M. (2008). Hemispheric differences in processing the literal interpretation of idioms: Converging evidence from behavioral and fMRI studies. Cortex, 44, 848-860.

McGlone, M., Glucksberg, S., \& Cacciari, C. (1994). Semantic productivity and idiom comprehension. Discourse Processes, 17, 167-190.

Miller, E. (2000). The prefrontal cortex and cognitive control. Nature Reviews Neuroscience, 1, 59-65.

Miller, E., \& Cohen, J. (2001). An integrative theory of prefrontal cortex function. Annual Reviews Neuroscience, 2001, 167-202.

Miller, L. M. S., \& Stine-Morrow, E. A. (1998). Aging and the effects of knowledge on on-line reading strategies. The Journals of Gerontology Series B: Psychological Sciences and Social Sciences, 53, 223-233. 
Miller, G., \& Johnson-Laird, P. (1976). Language and perception. Belknap Press.

Miyake, A., Just, M., \& Carpenter, P. (1994). Working memory constraints on the resolution of lexical ambiguity: Maintaining multiple interpretations in neutral contexts. Journal of Memory and Language, 33, 175-202.

Morrone, I., Declercq, C., Novella, J., \& Besche, C. (2010). Aging and inhibition processes: The case of metaphor treatment. Psychology and Aging, 25, 697-701.

Munoz, D., \& Everling, S. (2004). Look away: The anti-saccade task and the voluntary control of eye movements. Nature Reviews Neuroscience, 5, 218-228.

Neill, W. (1989). Lexical ambiguity and context: An activation-suppression model. In D. Gorfein (Ed.), Resolving Semantic Ambiguity (pp. 63-83). New York, NY: Springer.

Nippold, M. A., \& Rudzinski, M. (1993). Familiarity and Transparency in Idiom Explanation: A Developmental Study of Children and Adolescents. Journal of Speech, Language, and Hearing Research, 36, 728-737.

Nippold, M., Uhden, L., \& Schwarz, I. (1997). Proverb explanation through the lifespan: A developmental study of adolescents and adults. Journal of Speech, Language, and Hearing Research, 40, 245-253.

Norman, D., \& Shallice, T. (1986). Attention to action: Willed and automatic control of behavior. In R. Davidson, G. Schwartz, \& Shapiro, D. (Eds.), Consciousness and SelfRegulation: Advances in Research and Theory (pp. 1-18). New York, NY: Plenum.

Nunberg, G., Sag, I., \& Wasow, T. (1994). Idioms. Language, 70, 491-538.

Oldfield, R. (1971). The assessment and analysis of handedness: The Edinburgh inventory. Neuropsychologia, 9, 97-113. 
Oliveri, M., Romero, L., \& Papagno, C. (2004). Left but not right temporal involvement in opaque idiom comprehension: A repetitive transcranial magnetic stimulation study. Journal of Cognitive Neuroscience, 16, 848-855.

Onifer, W., \& Swinney, D. (1981). Accessing lexical ambiguities during sentence comprehension: Effects of frequency of meaning and contextual bias. Memory \& Cognition, 9, 225-236.

Ortony, A., Schallert, D., Reynolds, R., \& Antos, S. (1978). Interpreting metaphors and idioms: Some effects of context on comprehension. Journal of Verbal Learning and Verbal Behavior, 17, 465-477.

Papagno, C. (2010). Idiomatic language comprehension: Neuropsychological evidence. In M. Balconi (Ed.), Neuropsychology of communication (pp. 111-129). London, UK: Springer.

Papagno, C., \& Caporali, A. (2007). Testing idiom comprehension in aphasic patients: The effect of task and idiom type. Brain and Language, 100, 208-220.

Papagno, C., Lucchelli, F., Muggia, S., \& Rizzo, S. (2003). Idiom comprehension in Alzheimer's disease: The role of the central executive. Brain, 126, 2419-2430.

Papagno, C., \& Vallar, G. (2001). Understanding metaphors and idioms: A single-case neuropsychological study in a person with Down syndrome. Journal of the International Neuropsychological Society, 7, 516-527.

Pascual-Leone, A. (1999). Transcranial magnetic stimulation: Studying the brain-behaviour relationship by induction of 'virtual lesions'. Philosophical Transactions of the Royal Society B: Biological Sciences, 354, 1229-1238.

Pascual-Leone, A., Gates, J. R., \& Dhuna, A. (1991). Induction of speech arrest and counting errors with rapid-rate transcranial magnetic stimulation. Neurology, 41, 697-702. 
Paulesu, E., Frith, C., \& Frackowiak, R. (1993). The neural correlates of the verbal component of working memory. Nature, 362, 342-345.

Paulus, W. (2002). Transcranial direct current stimulation (tDCS). Supplements to Clinical Neurophysiology, 56, 249-254.

Paxton, J., Barch, D., Racine, C., \& Braver, T. (2008). Cognitive control, goal maintenance, and prefrontal function in healthy aging. Cerebral Cortex, 18, 1010-1028.

Perfetti, C. (2007). Reading ability: Lexical quality for comprehension. Scientific Studies of Reading, 11, 357-383.

Perfetti, C., \& Hart, L. (2002). The lexical quality hypothesis. In L. Verhoeven, C. Elbro, \& P. Reitsma (Eds.), Precursors of Functional Literacy (pp. 189-213). Amsterdam, the Netherlands: John Benjamins Publishing.

Pesciarelli, F., Gamberoni, T., Ferlazzo, F., Russo, L. L., Pedrazzi, F., Melati, E., \& Cacciari, C. (2014). Is the comprehension of idiomatic sentences indeed impaired in paranoid Schizophrenia? A window into semantic processing deficits. Frontiers in Human Neuroscience, 8 .

Petrides, M., \& Pandya, D. N. (1999). Dorsolateral prefrontal cortex: Comparative cytoarchitectonic analysis in the human and the macaque brain and corticocortical connection patterns. European Journal of Neuroscience, 11, 1011-1036.

Phelps, E. A., Hyder, F., Blamire, A. M., \& Shulman, R. G. (1997). FMRI of the prefrontal cortex during overt verbal fluency. Neuroreport, 8, 561-565.

Poldrack, R., Wagner, A., Prull, M., Desmond, J., Glover, G., \& Gabrieli, J. (1999). Functional specialization for semantic and phonological processing in the left inferior prefrontal cortex. NeuroImage, 10, 15-35. 
Posner, M., \& DiGirolamo, G. (1998). Executive attention: Conflict, target detection and cognitive control. In R. Parasuraman (Ed.), The Attentive Brain (pp. 401-423). Cambridge: MIT Press.

R Development Core Team. (2013). R: A language and environment for statistical computing. (Version 3.0.2) [Computer Software]. Vienna, Austria: R Foundation for Statistical Computing.

Rapp, A., Mutschler, D., \& Erb., M. (2012). Where in the brain is nonliteral language? A coordinate-based meta-analysis of functional magnetic resonance imaging studies. NeuroImage, 63, 600-610.

Rapp, A., Leube, D., Erb, M., Grodd, W., \& Kircher, T. (2004). Neural correlates of metaphor processing. Cognitive Brain Research, 20, 395-402.

Rassiga, C., Lucchelli, F., Crippa, F., \& Papagno, C. (2009). Ambiguous idiom comprehension in Alzheimer's disease. Journal of Clinical and Experimental Neuropsychology, 31, 402411.

Ratcliff, R. (1993). Methods for dealing with reaction time outliers. Psychological Bulletin, 114, 510-532.

Ridderinkhof, K., Ullsperger, M., Crone, E., \& Nieuwenhuis, S. (2004). The role of the medial frontal cortex in cognitive control. Science, 306, 443-447.

Ridderinkhof, K., van den Wildenberg, W., Segalowitz, S., \& Carter., C. (2004). Neurocognitive mechanisms of cognitive control: The role of prefrontal cortex in action selection, response inhibition, performance monitoring, and reward-based learning. Brain and Cognition, 56, $129-140$. 
Rizzo, S., Sandrini, M., \& Papagno, C. (2007). The dorsolateral prefrontal cortex in idiom interpretation: An rTMS study. Brain Research Bulletin, 71, 523-528.

Robert, C., Borella, E., Fagot, D., Lecerf, T., \& de Ribaupierre, A. (2009). Working memory and inhibitory control across the life span: Intrusion errors in the Reading Span test. Memory \& Cognition, 37, 336-345.

Rodd, J., Gaskell, M., \& Marslen-Wilson, W. (2004). Modelling the effects of semantic ambiguity in word recognition. Cognitive Science, 28, 89-104.

Rossi, S., Hallett, M., Rossini, P., \& Pascual-Leone, A. (2009). Safety, ethical considerations, and application guidelines for the use of transcranial magnetic stimulation in clinical practice and research. Clinical Neurophysiology, 120, 2008-2039.

Rosvold, H., Mirsky, A., Sarason, I., Bransome, E., \& Beck, L. (1956). A continuous performance test of brain damage. Journal of Consulting Psychology, 20, 343-350.

Sallet, J., Mars, R., Quilodran, R., Procyk, E., Petrides, M., \& Rushworth, M. (2012). Neuroanatomical basis of motivational and cognitive control: A focus on the medial and lateral prefrontal cortex. In R. Mars, J. Sallet, \& Rushworth, M. (Eds)., Neural basis of motivational and cognitive control, (pp. 5-20). Cambridge: MIT Press.

Salthouse, T. (1990). Working memory as a processing resource in cognitive aging. Developmental Review, 10, 101-124.

Salthouse, T. (1991). Mediation of adult age differences in cognition by reductions in working memory and speed of processing. Psychological Science, 2, 179-183.

Salthouse, T. (1996). The processing speed theory of adult age differences in cognition. Psychological Review, 103, 403-428. 
Salthouse, T. (2010). Selective review of cognitive aging. Journal of the International Neuropsychological Society, 16, 754-760.

Sanford, A., \& Graesser, A. (2006). Shallow processing and underspecification. Discourse Processes, 42, 99-108.

Sanford, A., \& Sturt, P. (2002). Depth of processing in language comprehension: Not noticing the evidence. TRENDS in Cognitive Sciences, 6, 382-386.

Saur, D., Kreher, B. W., Schnell, S., Kümmerer, D., Kellmeyer, P., Vry, M. S., ... \& Weiller, C. (2008). Ventral and dorsal pathways for language. Proceedings of the National Academy of Sciences, 105, 18035-18040.

Schaie, K. (1994). The course of adult intellectual development. American Psychologist, 49, 304313.

Schweigert, W. A. (1986). The comprehension of familiar and less familiar idioms. Journal of Psycholinguistic Research, 15, 33-45.

Sela, T., Ivry, R., \& Lavidor, M. (2012). Prefrontal control during a semantic decision task that involves idiom comprehension: A transcranial direct current stimulation study. Neuropsychologia, 50, 2271-2280.

Shum, M., Shiller, D., Baum, S., \& Gracco, V. (2011). Sensorimotor integration for speech motor learning involves the inferior parietal cortex. European Journal of Neuroscience, $34,1817-1822$.

Simon, J., \& Berbaum, K. (1990). Effect of conflicting cues on information processing: The 'Stroop effect'vs. the 'Simon effect'. Acta Psychologica, 73, 159-170.

Simon, J. R., \& Rudell, A. P. (1967). Auditory S-R compatibility: The effect of an irrelevant cue on information processing. Journal of Applied Psychology, 51, 300-304. 
Simon, J., \& Small A. (1969). Processing auditory information: Interference from an irrelevant cue. Journal of Applied Psychology, 53, 433.

Simpson, G. (1981). Meaning dominance and semantic context in the processing of lexical ambiguity. Journal of Verbal Learning and Verbal Behavior, 20, 120-136.

Simpson, G., \& Kang, H. (1994). Inhibitory processes in the recognition of homograph meanings. In D. Dagenbach \& T. Carr (Eds.), Inhibitory processes in attention, memory and language (pp. 359-381). San Diego, CA: Academic Press.

Siyanova-Chanturia, A., Conklin, K., \& Schmitt, N. (2011). Adding more fuel to the fire: An eye-tracking study of idiom processing by native and non-native speakers. Second Language Research, 27, 251-272.

Smolka, E., Rabanus, S., \& Rösler, F. (2007). Processing verbs in German idioms: Evidence against the configuration hypothesis. Metaphor and Symbol, 22, 213-231.

Sprenger, S. A., Levelt, W. J., \& Kempen, G. (2006). Lexical access during the production of idiomatic phrases. Journal of Memory and Language, 54, 161-184.

Stanovich, K., West, R., \& Harrison M. (1995). Knowledge growth and maintenance across the life span: The role of print exposure. Developmental Psychology, 31, 811-826.

Stine, E. A., \& Wingfield, A. (1994). Older adults can inhibit high-probability competitors in speech recognition. Aging and Cognition, 1, 152-157.

Stine-Morrow, E., Loveless, M., \& Soederberg, L. (1996). Resource allocation in on-line reading by younger and older adults. Psychology and Aging, 11, 475-486.

Stine-Morrow, E., Soederberg Miller, L., \& Hertzog, C. (2006). Aging and self-regulated language processing. Psychological Bulletin, 132, 582-606. 
Swinney, D. (1979). Lexical access during sentence comprehension: (Re)consideration of contextual effects. Journal of Verbal Learning and Verbal Behavior, 18, 645-659.

Swinney, D., \& Cutler, A. (1979). The access and processing of idiomatic expressions. Journal of Verbal Learning and Verbal Behavior, 18, 523-534.

Tabossi, P. (1988). Accessing lexical ambiguity in different types of sentential contexts. Journal of Memory and Language, 27, 324-340.

Tabossi, P., Fanari, R., \& Wolf, K. (2009). Why are idioms recognized fast? Memory \& Cognition, 37, 529-540.

Tanji, J., \& Hoshi, E. (2008). Role of the lateral prefrontal cortex in executive behavioral control. Physiological Reviews, 88, 37-57.

Thompson-Schill, S., Bedny, M., \& Goldberg, R. (2005). The frontal lobes and the regulation of mental activity. Current Opinion in Neurobiology, 15, 219-224.

Thompson-Schill, S., D’Esposito, M., Aguirre, G., \& Farah, M. (1997). Role of left inferior prefrontal cortex in retrieval of semantic knowledge: A reevaluation. Proceedings of the National Academy of Sciences, 94, 14792-14797.

Thompson-Schill, S., D'Esposito, M., \& Kan, I. (1999). Effects of repetition and competition on activity in left prefrontal cortex during word generation. Neuron, 23, 513-522.

Titone, D., Columbus, G., Whitford, V., Mercier, J., \& Libben, M. (2014). Contrasting bilingual and monolingual idiom processing. Bilingual Figurative Language, 171-207.

Titone, D. A., \& Connine, C. M. (1994). Comprehension of idiomatic expressions: Effects of predictability and literality. Journal of Experimental Psychology: Learning, Memory, and Cognition, 20, 1126. 
Titone, D., \& Connine, C. (1999). On the compositional and noncompositional nature of idiomatic expressions. Journal of Pragmatics, 31, 1655-1674.

Titone, D., Holzmann, P., \& Levy, D. (2002). Idiom processing in schizophrenia: literal implausibility saves the day for idiom priming. Journal of Abnormal Psychology, 111, 313-320.

Titone, D., \& Libben, M. (2014). Time-dependent effects of decomposability, familiarity and literal plausibility on idiom priming: A cross-modal priming investigation. The Mental Lexicon, 9, 473-496.

Tompkins, C., Baumgaertner, A., Lehman, M., \& Fassbinder, W. (2000). Mechanisms of discourse comprehension impairment after right hemisphere brain damage: Suppression and enhancement in lexical ambiguity resolution. Journal of Speech, Language and Hearing Research, 43, 62-78.

Tompkins, C., Boada, R., \& McGarry, K. (1992). The access and processing of familiar idioms by brain-damaged and normally aging adults. Journal of Speech and Hearing Research, $35,626-637$.

Trammel Neill, W. (1989). Lexical ambiguity and context: An activation-suppression model. In D. Gorfein (Ed.), Resolving Semantic Ambiguity (pp. 63-83). New York, NY: Springer.

Ueckermann, J., Thoma, D., \& Daum, I. (2008). Proverb interpretation changes in aging. Brain and Cognition, 67, 51-57.

Underwood, G., Schmitt, N., \& Galpin, A. (2004). The eyes have it: An eye-movement study into the processing of formulaic sequences. In N. Schmitt (Ed.), Formulaic sequences: Acquisition, processing, and use. John Benjamins Publishing. 
Van der Lubbe, R. \& Verleger, R. (2002). Aging and the Simon task. Psychophysiology, 39, 100110.

Van Dijk, T. A., \& Kintsch, W. (1983). Strategies of discourse comprehension. New York: Academic Press.

Volk, D. W., \& Lewis, D. A. (2010). Prefrontal cortical circuits in schizophrenia. In N. Swerdlow (Ed.), Behavioral Neurobiology of Schizophrenia and Its Treatment (pp. 485508). Heidelberg: Springer.

Wagner, A., Paré-Blagoev, E., Clark, J., \& Poldrack, R. (2001). Recovering meaning: Left prefrontal cortex guides controlled semantic retrieval. Neuron, 31, 329-338.

Walsh, V., \& Cowey, A. (2000). Transcranial magnetic stimulation and cognitive neuroscience. Nature Reviews Neuroscience, 1, 73-80.

Wassermann, E. (1998). Risk and safety of repetitive transcranial magnetic stimulation: Report and suggested guidelines from the International Workshop on the Safety of Repetitive Transcranial Magnetic Stimulation, June 5-7, 1996. Electroencephalography and Clinical Neurophysiology, 108, 1-16.

West, R. (1996). An application to prefrontal cortex function theory to cognitive aging. Psychological Bulletin, 120, 272-292.

West, R. (2003). Neural correlates of cognitive control and conflict detection in the Stroop and digit-location tasks. Neuropsychologia, 41, 1122-1135.

West, R., \& Alain, C. (2000). Age-related decline in inhibitory control contributes to the increased Stroop effect observed in older adults. Psychophysiology, 37, 179-189.

Westbury, C. \& Titone, D. (2011). Idiom literality judgments in younger and older adults: Agerelated effects in resolving semantic interference. Psychology and Aging, 26, 467-474. 
Whitney, C., Jefferies, E., \& Kircher, T. (2011). Heterogeneity of the left temporal lobe in semantic representation and control: Priming multiple versus single meanings of ambiguous words. Cerebral Cortex, 21, 831-844.

Whitney, C., Kirk, M., O’Sullivan, Lambon Ralph, M., Jefferies, E. (2011). The neural organization of semantic control: TMS evidence for a distributed network in left inferior and posterior middle gyrus. Cerebral Cortex, 21, 1066-1075.

Whitney, C., Kirk, M., O’Sullivan, J., Lambon Ralph, M., \& Jefferies, E. (2012). Executing semantic processing is underpinned by a large-scale neural network: revealing the contribution of left prefrontal, posterior, temporal, and parietal cortex to controlled retrieval and selection using TMS. Journal of Cognitive Neuroscience, 24, 133-147.

Wingfield, A., Aberdeen, J. S., \& Stine, E. (1991). Word onset gating and linguistic context in spoken word recognition by young and elderly adults. Journal of Gerontology, 46, 127129.

Winner, E., \& Gardner, H. (1977). The comprehension of metaphor in brain-damaged patients. Brain, 100, 717-729.

Wood, J., \& Grafman, J. (2003). Human prefrontal cortex: Processing and representational perspectives. Nature Reviews Neuroscience, 4, 139-147.

Yarkoni, T. (2011). Functional MRI in Health Psychology and beyond: A call for caution. European Health Psychologist, 13, 61-64.

Yarkoni, T., \& Braver, T. S. (2010). Cognitive neuroscience approaches to individual differences in working memory and executive control: Conceptual and methodological issues. In A. Gruszka, G. Matthews, \& B. Szymura (Eds.), Handbook of Individual Differences in Cognition (pp. 87-107). New York: Springer. 
Yeung, N. (2013). Conflict monitoring and cognitive control. In K. Ochsner \& Stephen Kosslyn (Eds.), Oxford Handbook of Cognitive Neuroscience (Vol. 2, pp. 275-299). New York, NY: Oxford University Press.

Yousry, T., Schmid, U., Alkadhi, H., Schmidt, D., Peraud, A., Buettner, A., \& Winkler, P. (1997). Localization of the motor hand area to a knob on the precentral gyrus: A new landmark. Brain, 120, 141-157.

Zempleni, M.-Z., Haverkort, M., \& Renken, R., \& Stowe, L. (2007). Evidence for bilateral involvement in idiom comprehension: An fMRI study. NeuroImage, 34, 1280-1291.

Zorzi, M., \& Umiltá, C. (1995). A computational model of the Simon effect. Psychological Research, 58, 193-205. 